

\title{
Microchip electrophoresis and electrochemical detection: A review on a growing synergistic implementation
}

Brenda Maria de Castro Costa, Sophie Griveau, Fanny d'Orlye, Fethi Bedioui, José Alberto Fracassi da Silva, Anne Varenne

\section{- To cite this version:}

Brenda Maria de Castro Costa, Sophie Griveau, Fanny d'Orlye, Fethi Bedioui, José Alberto Fracassi da Silva, et al.. Microchip electrophoresis and electrochemical detection: A review on a growing synergistic implementation. Electrochimica Acta, 2021, 391, pp.138928. 10.1016/j.electacta.2021.138928 . hal-03412684

\section{HAL Id: hal-03412684 \\ https://hal.science/hal-03412684}

Submitted on 3 Nov 2021

HAL is a multi-disciplinary open access archive for the deposit and dissemination of scientific research documents, whether they are published or not. The documents may come from teaching and research institutions in France or abroad, or from public or private research centers.
L'archive ouverte pluridisciplinaire HAL, est destinée au dépôt et à la diffusion de documents scientifiques de niveau recherche, publiés ou non, émanant des établissements d'enseignement et de recherche français ou étrangers, des laboratoires publics ou privés. 


\title{
Microchip Electrophoresis and Electrochemical Detection: a Review on a Growing Synergistic Implementation
}

Brenda Maria De CASTRO COSTA $^{1,2}$, Sophie GRIVEAU ${ }^{1}$, Fanny d'ORLYE ${ }^{1}$, Fethi BEDIOUI $^{1}$, José Alberto FRACASSI da SILVA ${ }^{2, *}$ and Anne VARENNE ${ }^{1, *}$

${ }^{1}$ Chimie ParisTech PSL, CNRS 8060, Institute of Chemistry for Life and Health (i-CLeHS), Paris, France

${ }^{2}$ Department of Analytical Chemistry-Chemistry Institute, State University of Campinas, Campinas, SP, Brazil.

$\begin{array}{llll}* \text { *orresponding } \quad \text { authors: } & \text { fracassi@iqm.unicamp.br } & \text { (J.A.F.S); }\end{array}$ anne.varenne@ chimieparistech.psl.eu (A.V.)

Keywords: microchip; electrophoresis; amperometry; conductimetry; lab-on-chip; microfluidics; electrodes.

\begin{abstract}
Microchip capillary electrophoresis (MCE) with integrated electrodes to perform electrochemical (EC) sensing is a powerful tool for fundamental research and practical applications that are increasingly in demand. In this critical review, we discuss the main strategies developed over the last twenty years to design complete MCE-EC devices. First, we outline all the questions raised by the pioneering research groups regarding the coupling of these two techniques in microfluidic devices. Then, we present all the key-solutions, in the form of strategies, that our colleagues have cleverly elaborated to make these devices evolve into elaborate and relevant tools. These evolutions have mainly focused on the nature of the electrodes used, their configuration, the process of their fabrication, their integration and positioning in the microfluidic systems and their performance within the integrated devices. Particular attention is paid to the adequacy of the materials of the microsystems and the electrodes and to the resolution of the electrical interference between the electric fields necessary for the electrophoretic separation and the electrochemical detection. Finally, we describe significant examples of methodologies for the analysis of complex biological, food and environmental samples, highlighting the analytical improvements brought by these MCEEC systems.
\end{abstract}


List of abbreviation

$\mathrm{AE}$ - auxiliary electrode

BDD - boron doped diamond

$\mathrm{C}^{4} \mathrm{D}$ - capacitively coupled contactless conductivity detector

CA - catechol

CB-NPs - carbon black nanoparticle

CCD - contactless conductivity detector

CE - capillary electrophoresis

$\mathrm{CF}$ - carbon fiber,

CFNE - carbon fiber nanoelectrodes

CI - carbon ink

CNT - carbon nanotube electrodes

$\mathrm{CP}$ - carbon paste

$\mathrm{CV}$ - cyclic voltammetry

CySNO - S-nitrosocysteine

CZE - capillary zone electrophoresis

DA - dopamine

DPV - differential pulse voltammetry

EC- Electrochemical

EDS - energy dispersive X-ray spectra

EOF - electroosmotic flow

FE-SEM - field emission scanning electron microscope

$\mathrm{GC}$ - glass carbon

GO - graphene oxide

GSNO - S-nitrosoglutathione

HbaA1c mAb - anti-human hemoglobin-A1c antibody

HTGC - heat-treated glassy carbon

LC - liquid chromatography

List of abbreviations

LOD - limit of detection

LSV - linear sweep voltammetry 
MCE - Microchip capillary electrophoresis

MD - microdialysis

MW - multi-walled

ORMOCERs - organically modified ceramic polymers

PC - polycarbonate

PDMS - polydimethylsiloxane

PMMA - polymethyl methacrylate

POC - point-of-care

PPF - pyrolyzed photoresist film

PVAc - poly(vinyl acetate)

$\mathrm{RE}$ - reference electrode

RMS - Root Mean Square

RSD - relative standard deviation

RSNO - S-nitrosothiols

$\mathrm{S} / \mathrm{N}$ - signal-to-noise

SEM - scanning electron microscopy

SW - Single-walled

$\mathrm{T}_{\mathrm{g}}$ - glass transition temperature

WE - working electrode

\section{Introduction to pioneering studies}

Miniaturization in chemical and biomedical analysis has emerged in recent years aiming at surpassing the performance of conventional analytical devices through the reduction of reagents, samples, waste, analysis time, production costs and contamination risks, as well as designing automated and portable devices that would be used in any part of the world without technical expertise or specific experimental conditions. The improvements of chemical etching techniques and photolithography have greatly contributed to the emergence of this field of research.

As early as 1979, Terry et al. published a microfabrication strategy using photolithographic patterning processes for the integration of a gas chromatograph and a thermal conductivity detector onto an entire silicon wafer [1]. This work went unrecognized for over a decade before a novel concept was developed by Manz et al. [2] so-called 
Miniaturized Total Analysis Systems ( $\mu$-TAS), which involves sampling, sample pretreatment, separation and detection performed within a single microdevice. These miniaturized systems had a tremendous impact on different research fields, for instance in analytical chemistry, as they deal with very small sample and reagents volumes, high resolution and sensitivity separations, low fabrication cost, small footprints and decrease of the physical size of the systems (portability) [3]. Among them, particular attention has been given to electro-driven separations of target analytes. Indeed, microchip capillary electrophoresis (MCE) represents the next generation of miniaturized devices, for the separation of complex sample matrices. The fact is that the electrokinetic separations are easily miniaturized, require a single high voltage sequencer, and offer a flexible and simple procedure and short analysis time [4].

As concerning the detection step, different techniques can be implemented. Fluorescence, which is classically used in microsystems, has several drawbacks, such as native fluorescence of the device material and samples, need for sample labelling, and it is limited to compounds which fluoresce or are amenable to derivatization with a fluorophore $[5,6]$. Colorimetry is mainly used when a positive/negative diagnostic is required. Mass spectrometry, still difficult to couple to a microfluidic system, could help for molecular identification and quantitation. Surface Enhanced Raman Spectroscopy is a highly sensitive detection mode but still has a poor reproducibility [7]. Infrared is suitable for solid samples analysis since it is not necessary to dilute or destroy them to perform the analysis. But it is not suitable for fluidic systems, since the samples are in solution, the absorption from the solvent can drastically saturate the IR signal [8].

Electrochemical (EC) detection is a good alternative to be used with both conventional capillary electrophoresis (CE) and MCE, which is intrinsically simpler than, for example, optical methods. Indeed, an electrical signal is acquired directly without the use of intermediate physical parameter, for instance radiation intensity. Also, the detector hardware consists of small electrodes and some simple electronic circuits, whereas for mass spectrometry a large instrumentation is necessary. And the most notable benefit of EC detection is the fact that its advantages when is coupled with $\mathrm{CE}$ and MCE systems are conserved. EC detection was first implemented in classical CE, such as silicon and glass microstructures integrating separation and detection electrodes into CE capillaries and MCE platforms [9-11]. Ultramicroelectrodes can be fabricated directly in the channel platform or externally to it, and portable, isolated potentiostats are commercially available. The main EC detection modes developed with CE are conductometry and amperometry. Virtanen was the 
first to develop an electrochemical detector for CE in 1974 [12], reporting a potentiometric detector of $200 \mu \mathrm{m}$ large bore columns. The system was composed by an $\mathrm{Ag} / \mathrm{AgCl}$ coated platinum wire as the WE and the potential was measured with respect to a platinum wire pseudo-reference electrode (RE) by a dc Wheat-stone bridge circuit. This detection system performed a quantitative study of small inorganic ions such as $\mathrm{K}^{+}, \mathrm{Na}^{+}$and $\mathrm{Li}^{+}$.

When it comes to use amperometry and voltammetry for selective and sensitive monitoring of redox active target analytes without any derivatization, the electric field produced inside the channel for the separation purpose can be of some orders of magnitude greater than the one involved in the detection. Thus, there is a need to develop smart technical approaches to overcome this challenge in interfacing amperometric/voltammetric detection to CE. Walling and Ewing were the first authors to apply amperometric detection to CE [13]. They created an electrically conductive porous glass joint in the column near by the end of the capillary and the detection was accomplished at the very end of capillary, downstream the conductive joint. By this way, the constraints of interfacing high voltage electric fields are removed. In other words, conductive joint decouples the electrochemical detector from the separation voltage. The authors used a single carbon fiber $(10 \mu \mathrm{m})$ as WE, which was placed at the end of the CE capillary to detect catechol and several catecholamines, with a 5 pmol /injection as limit of detection (LOD).

Besides amperometry and voltammetry, conductivity measurements were also developed as they allow monitoring any analyte irrespective of whether it is electroactive or not. It gains its acceptance from its universality and is particularly useful for non-electroactive species or not readily detectable by UV absorption. The main requirement is that the migrating analyte has a conductivity different from that of the carrier electrolyte. Mikkers $e t$ al. [14] reported the first work using the conductivity measurement as detection mode in CE. The authors separated 16 compounds, including organic and inorganic ions, using a narrowbore tubes with $200 \mu \mathrm{m}$ of internal diameter.

Coupling MCE and EC systems empowers all common advantages related to miniaturization, portability, low sample and reagent consumption and high throughput. The alliance between microfluidics, MCE and electrochemistry constitutes now an attractive approach since it offers a synergistic effect over each inherent feature enhancing their potential and offering a unique technology $[15,16]$. The electrochemical techniques are indeed well suited for miniaturization without losses in their analytical performances. Even more some of their analytical performances may be enhanced as the processes are confined within 
the microfluidic structure [17-20]. An illustration of a MCE and EC detection is presented in Figure 1.

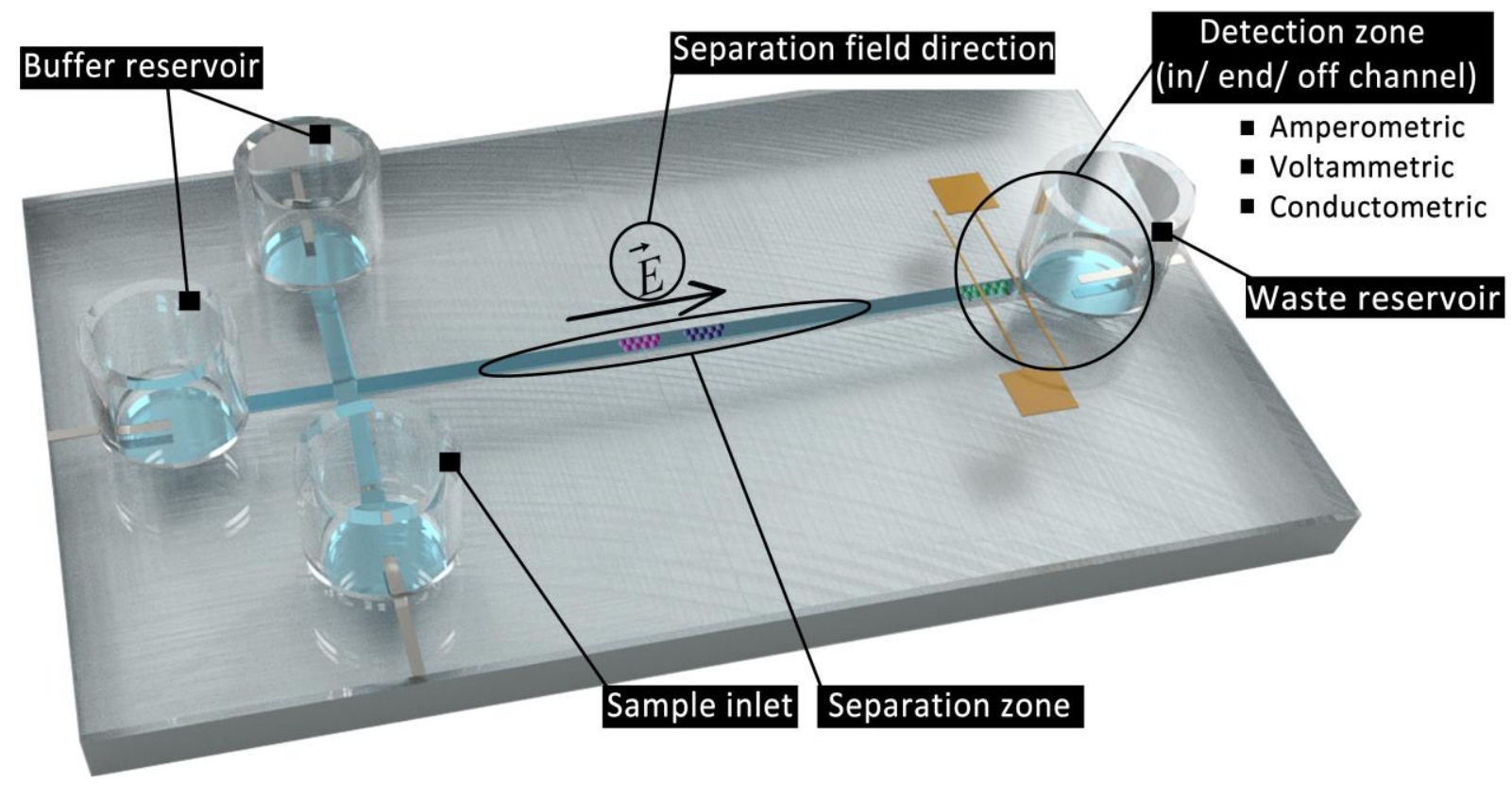

Figure 1. General scheme of an MCE device with integrated electrodes to perform EC detection.

EC detection with integrated electrodes was first used in MCE systems by Mathies et al. [21]. The authors published a patent which includes a microfabricated capillary electrophoresis with integrated amperometric detection. The device consists of thin-band $\mathrm{Pt}$ WE $(10 \mu \mathrm{m}$ wide) placed just beyond the end of the separation channel. The channel was photolithographically defined to minimize the effect of the separation voltage on the EC detection. The distance between the outlet of the separation channel and the WE (detector) ranged from $\approx 50$ to $1000 \mu \mathrm{m}$. This electrode configuration decouples the detector from the separation voltage, eliminates the problem of electrolysis (gas bubbles) in the separation channel (see more details about the decoupler issues in section 3), and minimizes the background noise as well at the WE owing to separation field. It should be noted that in this alignment, target species may diffuse into the waste reservoir as they come out the channel before being detected, which may lead to band broadening, asymmetric peak shapes, loss of resolution, and reduction of the signal intensity as a consequence of the dilution effect. $\mathrm{Pt}$ wires were included in the reservoirs to provide electrical connections to the separation and injection channels in glass substrate. The authors reported then on the first study of a fully integrated separation and detection device [22] for the analysis of dopamine, epinephrine, and 
catechol in less than $100 \mathrm{~s}$ and achieved limit of detection LOD's of 3.7, 6.5, and $12 \mu \mathrm{M}$, respectively.

The first study on conductivity detection in microfluidic devices after the introduction of the $\mu$ TAS concept was described in 1998. Both Baldock et al. [23] and Fielden et al. [24] reported on a PDMS device with integrated electrodes to perform isotachophoresis to separate three anionic dyes (amaranth, bromophenol blue and fluorescein) and transition metal ions ( $\mathrm{Mn}, \mathrm{Co}$ and $\mathrm{Ni}$ ), respectively. These microchips were sealed on top of a printed circuit board containing two parallel gold electrodes (100 $\mu \mathrm{m}$ width) as sensing electrodes. Later on, a significant contribution to conductivity detection for CE and MCE systems was made by Zemann et al. [25] and da Silva and do Lago [26] groups in 1998 by the introduction of the capacitively coupled contactless conductivity detector $\left(C^{4} D\right)$ in capillary zone electrophoresis (CZE). In this detection mode, the electrodes are not in direct contact with the solution. In 2001, Guijt et al. reported the first article on contactless conductivity detector for glass MCE [27]. The titanium electrodes ( $30 \mu \mathrm{m}$ width) were covered with silicon nitrite layer to perform contactless detection. Separation of two short peptides was achieved with a $7 \mu$ M LOD for each peptide.

EC detection is however poorly developed in MCE as significant electrical interferences may occur. All the pioneering reported studies mentioned before had to deal with problems that complicate the development of coupling between microfluidics, electrokinetic separations and EC. Thus, this field of research still faces many challenges to make these devices suitable for high throughput microfabrication and routine analytical applications. We address here the recent strategies of the last two decades employed to integrate electrodes of various shapes, compositions and materials in different microchip formats and materials with a critical comparison of their microfabrication process and their inherent advantages and limitations for MCE. At the same time, this is a comprehensive review which will highlight the new approaches to deal with classical issues provided by MCE-EC systems, such as:

- How the compatibility of the electrode nature with the substrate of the microfluidic device will narrow the options of materials and impact the coupling of the techniques.

- How the three major electrode positioning for amperometric detection (in-, end-, and off- channel electrode alignment) will lead the fabrication process.

This review focuses only on integrated electrodes for detection purpose, the electrodes used to provide electrical connections to the separation and injection channels will not be 
addressed, since most of the approaches use external Pt wires placed into reservoirs to apply the separation voltage. The main applications will also be described and analytical features promoted by MCE-EC systems will be precisely discussed in the applications section. This overview should help the community to select the appropriate device for MCE integrating EC detection for diagnostic purposes or to go further in their improvement in light of the critical description of the strategies.

\section{Electrode materials in microsystems}

On one hand, electrodes in micrometric format offer a significant advantage over the classical ones: the diffusion process of analytes at the electrode-liquid interface is different in millimetric and micrometric electrodes and leads to an increase in the signal-to-noise $(\mathrm{S} / \mathrm{N})$ ratio when the electrode size decreases. On the other hand, their integration onto plastic and glass chips can impressively enhance the automation, minimizes contamination for highthroughput screening and point-of-care (POC) devices and has promise for on-site investigation. However, the integration of electrodes within the microdevice is challenging from the process point of view, as their passivation and clean steps, isolation, geometry and position within the microsystems constitute major issues.

MCE separations were historically manufactured in glass [28] or silicon [29], the use of these materials steamed from their compatibility with photolithographic protocols and their similarity to fused silica. Currently, these devices are being performed in a diversity of materials and formats, including soft polymers such as polydimethylsiloxane (PDMS) [30], thermoplastic polymers [31], thermoset polymers [32], hybrid devices [33], photopolymers [34] and paper [35].

The selection of the substrate materials is evaluated through relevant physico-chemical properties, for instance UV-vis absorption properties, autofluorescence levels, glass transition temperature $\left(\mathrm{T}_{\mathrm{g}}\right)$, hydrophobicity / hydrophilicity and surface charge density allowing for electroosmotic flow (EOF). In addition, the substrates might have to undergo surface chemical modifications using solvents or plasma to improve bonding, reduce deformation and create specific functional groups. Furthermore, surface modification of the walls of the channels can be selected so as to improve electrophoretic separation efficiency by reducing analyte-wall interactions and increase EOF control.

Glass substrate has therefore found widespread use in microfluidic devices owing to its surface stability, optical transparency, chemical resistance, electrical insulation, and biological compatibility. It was the first substrate to be used to carry electrophoretic separations on a 
chip as described by Manz et al. [36] and the first material for MCE platform with integrated electrodes as reported by Woolley and co-workers[22]. In this later case, Pt electrodes were photolithographically patterned onto glass in a 2-electrode configuration using end-channel alignment. However, glass microfluidic fabrication procedures are commonly complex, requiring specific clean rooms and high temperature to seal the device.

In order to meet the academic community demand, for inexpensive and easily microfabricated microfluidic devices, Duffy et. al. [37] reported an easy procedure to fabricate microfluidic systems in a PDMS material. PDMS became then a widely used elastomer in early-stage microfluidics research due to its properties, such as optical transparency, ease microfabrication (soft-lithography), biocompatibility and possible exchange of oxygen with the environment. Liu et. al. [38] were the first to design and microfabricate PDMS device with integrated electrodes. The authors illustrated a PDMS membrane which was hermetically stuck to the glass wafer with engraved Pt electrodes and manufactured an integrated PDMSglass microchip. Soft lithography is nowadays the most common manufacturing process, as it is well established in the literature [39,40]. Recently, Coltro's group [41] proposed a new process for cost-effective fabrication of PDMS-MCE devices using poly(vinyl acetate) (PVAc) emulsion as photoresist master. The proof-of-concept was demonstrated with the electrophoretic separation and $\mathrm{C}^{4} \mathrm{D}$ detection of inorganic cations using $\mathrm{Cu}$ strip as sensing electrodes.

The use of polymeric materials shows a great potential to fabricate disposable systems in a large-scale high-quality production, since their introduction into industrial use in the 1930s. For this reason, much of the microfluidics research targeting commercial applications have dedicated their efforts to create devices using rigid polymers, as reported in the reviews by Genctick et al. [42] and Tsao[32]. In particular, polymethyl methacrylate (PMMA) is one of the most privileged materials as it is well-known from the generation of micro-optical devices as a low-cost material compared to silicon or glass substrate, with higher hydrophobicity than that of usual plastic materials, and showing a good hydrolytic stability compared to the limited stability of PDMS chips. Its main constraint is its low stability at high temperatures and high $\mathrm{pH}$-values.

Microfluidic paper-based analytical device $(\mu \mathrm{PAD})$ is a concept developed by Whitesides [43]. $\mu$ PADs began as a simple idea with an ambitious goal: replacing substrates such as plastic and glass to manufacture cheap microfluidic devices. Paper brings its own inherent advantages, for instance low cost, operational simplicity, and ease of acquisition. The development of EC paper-based devices has received considerable attention since Dungchai's 
et al. [44] publication in 2009. The authors demonstrated a paper-based device integrating screen-printed carbon-based electrodes to determinate glucose, lactate and uric acid in biological samples.

The nature of the electrode material is an important issue in MCE-EC. Namely the material selection will narrow the number of available substrates which can be used to manufacture the device. Also, the use of different materials can be explored to increase the selectivity and specificity of MCE, since the electrochemical response is highly dependent on the medium, the target analyte and electrode material.

In this section, readers will find electrodes classified into three main categories: bare metal-based electrodes; carbon-based electrodes and chemically modified electrodes. Respective information concerning the manufacturing, integration, characterization, and intrinsic properties of each material will be given.

\subsection{Bare metal electrodes}

The main metal electrodes usually employed in MCE-EC are $\mathrm{Pt}, \mathrm{Pd}, \mathrm{Au}, \mathrm{Cu}$, and $\mathrm{Ag}$. Classical lithography techniques can be used to define the electrode area prior to depositing the metal onto the surface directly or into an etched channel. Their fabrication is well described in the literature. Even if these electrodes are expensive to buy or manufacture, they can lead to mass production[45-47].

A large number of metals require an adhesion layer (usually $\mathrm{Ti}, \mathrm{Cr}$, nichrome, or $\mathrm{Ta}$ ), which are metals with high binding strength with oxygen and therefore allow several surfaces of materials to adhere onto the underlying substrate. This requirement limits their use with allPDMS devices, as the metals fracture due to substrate flexibility [48]. The metal electrodes are therefore commonly fabricated on glass substrates coated with chrome and positive photoresist. The desired electrode geometry is patterned using a transparency mask and a UV radiation. After the development of the photoresist, the underlying chrome layer is etched away using chrome etchant. Using a buffered oxidant, the glass is thus engraved. Finally, a thin layer of an adhesion metal is deposited in the engraved part followed by the deposition of the desired metal electrode, by sputtering and/or evaporation (Figure 2). The extra metal, photoresist, and chrome film are removed to achieve the patterning of metal electrode supported on glass. 


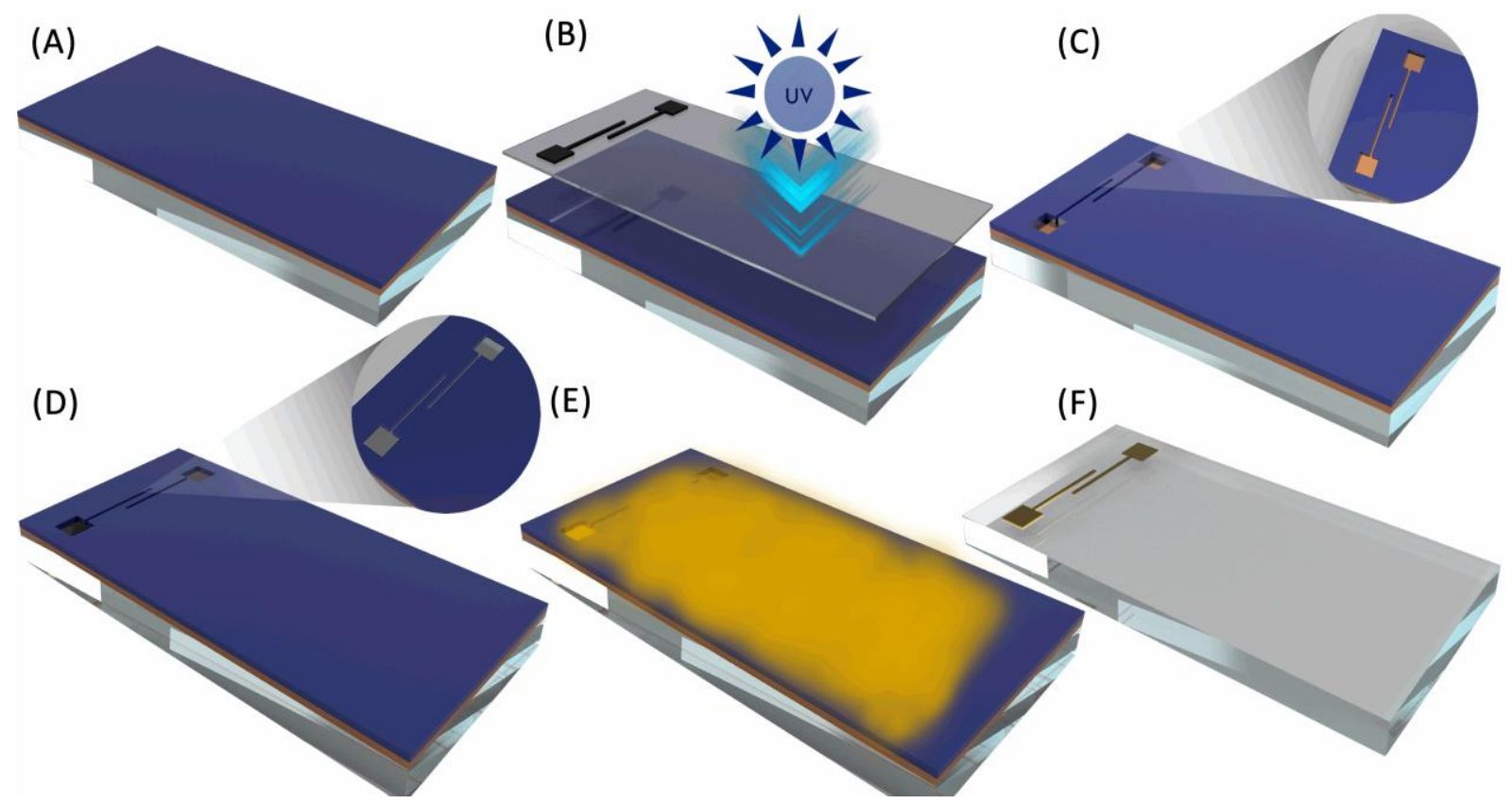

Figure 2. Assembly of metal electrodes onto a glass substrate; A. Glass substrate covered with a chrome layer and negative photoresist; B. A mask with the desired features is placed over the substrate and exposed with UV light; $\mathbf{C}$. The photoresist is developed; D. The underlying chrome layer is removed by chrome etchant and the glass exposed is etched to produce a trench by a buffered oxidant.; E. The adhesion metal and/or desired electrode metal is deposited onto the substrate; F. Finally, excess photoresist and chrome are removed from the substrate and the metal electrode remains.

Concerning the deposition of the adhesion metal and/or desired metal electrode, the most classical technique is the use of a thin film deposition approach, which is a vacuum technology for applying coatings of pure materials to the surface of substrates. The thickness of the coatings is commonly in the range of angstroms to microns and the deposited electrodes can be of a single material, or multiple materials in a layered structure. Depending on the selected electrode material, sputtering or evaporation technique can be employed.

The sputtering method involves the introduction of a controlled inert gas, such as argon, into a vacuum chamber, and electrical energization of a cathode to establish a selfsustaining plasma. The exposed surface of the cathode contains the material that will coat the substrate. The gas atoms inside the plasma turn into positively charged ions, which are then accelerated directly into the target metal. The impact promotes the release of atoms of the target material which travel to the substrate, condense, and form a thin layer. Gunasekara et al. [49] reported the manufacture of dual Pt electrodes in PDMS/glass MCE device. Before the sputtering process, the authors created a pattern etched on glass using a buffered oxide etchant. When dried, it was then exposed to oxygen plasma in order to promote adhesion of the etched glass surface. The glass plate was then placed for the sputtering process and the excess metal around the electrode was lifted off in an acetone bath. The lift-off process is 
widely used for dissolving the underlying positive resist layer, allowing for the patterning of the electrode material $[50,51]$. The metal deposition on substrates other than glass by sputtering techniques was also described. Bonabi et al. [52] developed metallization processes for organically modified ceramic polymers (ORMOCERs) for microfluidic electrochemical assays. The authors optimized all the parameters used for $\mathrm{Cr}$ and $\mathrm{Pt}$ deposition by sputtering, such as DC power, argon flow and time for a better adhesion of the layers. The deposited thin film was characterized by measuring its electrical conductivity. The feasibility of the developed metallization for implementation of microfluidic was validated by performing the determination of acetaminophen using a MCE-EC analytical system.

As concerning the evaporation process, the source material is evaporated under vacuum, allowing vapor particles to be deposited directly onto substrate, where vapor condense back to a solid state, forming a functional coating. In high-vacuum evaporation, electrical beam or electrical heating is used to melt, and evaporate the target materials. The vapor of the target material travels directly to the surface of the substrate, for example a glass, and gradually cools down to form a thin film layer [53]. Chen et al. [54] fabricated nanoband gold electrodes on SU-8 substrate via photolithography and metal vapor deposition. The strategy was to use a negative photoresist without baking step in order to avoid a strong bonding between SU-8 substrate and the wafer. After the metal deposition by using a thermal evaporator, the Au-coated SU-8 substrate was easily peeled from the wafer and the edge of the Au rather than the planar surface was used as a nanoband electrode. A characterization by an energy dispersive X-ray spectra (EDS) analysis using a field emission scanning electron microscope (FE-SEM) confirmed the gold distribution on the edge of the substrate, with a 100 $\mathrm{nm}$ width of the gold band. Moreover, the authors used an adhesion layer composed of $\mathrm{Cr}$ for Au electrode. Indeed, $\mathrm{Cr}$ (and also Ti) is widely used as an adhesion promoter as it is a more reactive metal than $\mathrm{Au}$ itself, and thus it increases the mechanical resistance of the electrode [55].

Although these techniques allow obtaining high resolution (nanoband features can be created) and appropriate material deposition for detection (homogeneous deposition), they suffer from an important limiting factor which is the substrate heating. Deposition by sputtering leads to two main sources of substrate heating: the heat for condensation and the kinetic energy of the incident atoms and ions. Due to the heating by energetic atoms and ions, sputtering heats the substrate more than evaporation at higher deposition rates. Therefore, this technique could not be used for substrates with low glass transition temperature, for instance polymers [56]. 
The conventional hot embossing is a process which can be used to pattern the electrodes and prepare the microchip polymeric material. Briefly, the process consists in placing the substrate, such as a polymer, on a lower plate and a master stamp is attached on an upper one. The polymeric substrate is heated above its $\mathrm{T}_{\mathrm{g}}$. Subsequently, a load is applied on the substrate through the upper plate and the plates are held for some time then temperature and load are reduced, the master stamp is separated from the substrate and the pattern on the master stamp is transferred to the substrate [57]. Wei et al. [58] developed a thread-based MCE system with 3D detecting electrodes. The authors reported the integration of $\mathrm{Cr} / \mathrm{Au}$ electrodes (300 $\mu \mathrm{m}$ width) in PMMA substrate with hot embossing and sputtering procedure. To manufacture the electrodes, prior to the hot embossing process, a piece of thin aluminium foil was placed between the master mold and the substrate as a sandwich structure. The aluminium foil was used as a demoulding layer that acted as a mask for metal sputtering (Figure 3.1). This simple approach allows fabrication of 3D electrodes, resulting in a high contact surface area for electrochemical detection and finally enhancing the current response without compromising separation efficiency. Figure 3.2 presents the separation of dopamine (DA) and catechol (CA) using both 2D and 3D electrode chips. The peaks obtained with 3D electrode exhibited a sharp and high current response. Furthermore, S/N ratio increased by a factor of five, and the calculated plate number was 1.5 times increased when an MCE is implemented with 3D electrodes for detection purpose.

1)

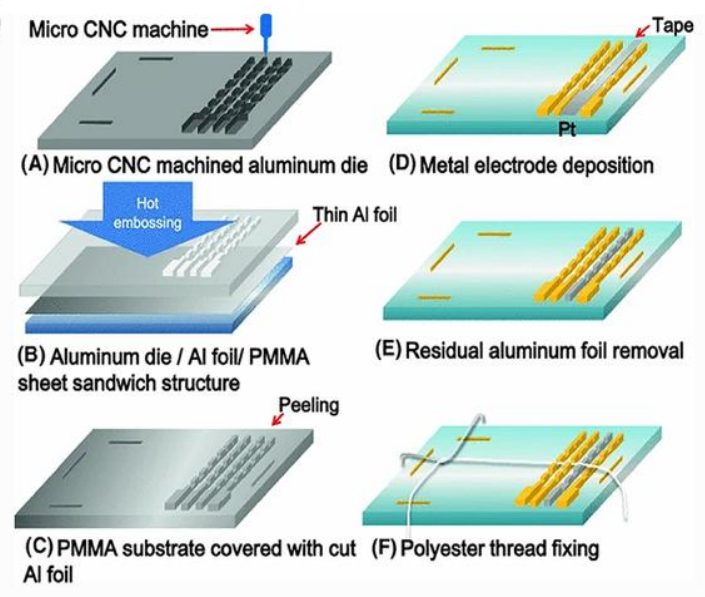

2)
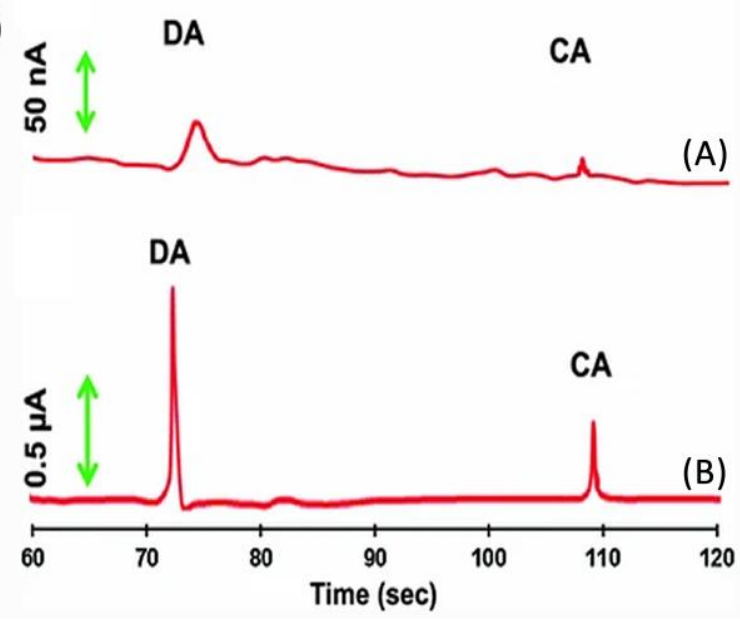

Figure 3. Scheme summarizing the fabrication steps for the thread-based MCE. 1A. In a PMMA substrate a concave master mold is fabricated in an $\mathrm{Al}$ alloy via micro-CNC machine; 1B. Before the hot embossing process, a piece of thin aluminium foil is placed between the master mold and the PMMA substrate; 1C. The Al foil is used as a mask for metal sputtering. The hot embossing process produced protruding EC electrodes, which are covered with the foil after the procedure. The Al foil on the third electrode ( (RE) electrode) is then peeled off and sputtered with $\mathrm{Cr} / \mathrm{Pt}$ layers; 1D. The RE electrode is covered with an electrostatic tape, and the others were again sputtered with $\mathrm{Cr} / \mathrm{Au}$ layers; $\mathbf{1 E}$. The residual $\mathrm{Al}$ foil was then stripped from the PMMA; 1F. Polyester threads are assembled onto substrate to perform a channel. Electropherograms of a sample containing dopamine (DA) and catechol (CA) using a 2A. bidimensional electrode and 2B. three-dimensional electrode[58] . Reprint by permission from Spring Nature. 
The use of epoxy-embedded electrodes to integrate electrochemical detection was developed by Selimovic et al. [59] and metal electrodes may be incorporated using this technique. Briefly, a metal gold wire (electrode) is placed into the hole of a Teflon mold in a vertical orientation (Figure 4A). Following the assembly of the mold and electrode, a thoroughly mixed combination of resin and an activator is poured into the mold (Figure 4B). When the mixture is cured, the electrode-containing epoxy substrate is removed (Figure 4C). The substrate is then polished using a wet grinder to create a useable substrate bearing on its underneath a disc shaped electrode (Figure 4D). Finally, the disc electrode surface is reversibly sealed under PDMS fluidic network (Figure 4E) allowing its alignment with the microchannel. To increase the surface area of the embedded $25 \mu \mathrm{m}$ diameter electrode (Figure $4 \mathrm{~F}$ ), gold electrodepositions were performed and then characterized by confocal image (Figure $4 \mathrm{G})$. The surface area was determined using cyclic voltammetry $\left(1.54 \times 10^{-4} \mathrm{~cm}^{2}\right)$, which is considerably larger than the geometrically calculated area $\left(4.9 \times 10^{-6} \mathrm{~cm}^{2}\right)$. The same procedure can be used for polystyrene-embedded electrodes. This fabrication method allows the electrode to be polished before each use for surface cleaning, and a top layer containing the separation channels can be aligned on the surface of the substrate. More recently, Jonson et al. [60] reported the same microfabrication embedded electrodes process to integrate a carbon-based WE and metal-based decoupler in a single step. The device was employed for amperometric detection of dopamine, epinephrine, catechol, and 3,4-dihydroxyphenylacetic acid. Whereas the electrode fabrication processes generally report the creation of band electrodes, the authors explored the production of disk electrodes. 

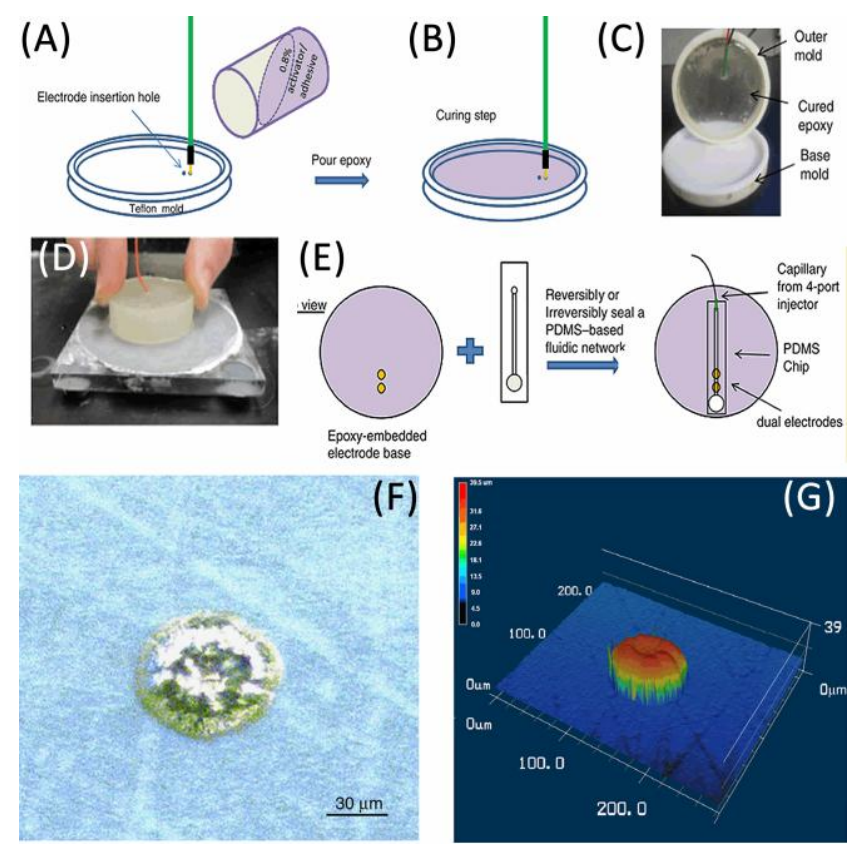

Figure 4. Fabrication of embedded electrodes: A. A gold wire is inserted into the Teflon master mold; B. An epoxy mixture is placed into the mold and left to cure; C. The base of Teflon mold is removed from epoxy, with the outer mold still remaining; D. The electrode is polished to generate a fresh electrode surface. The device is assembled: E. The epoxyembedded electrode is sealed to a PDMS containing the channel; F. Micrograph of a gold pillar electrode; G. Confocal image of the pillar electrode (height $=27 \mu \mathrm{m}$, width $=65 \mu \mathrm{m}$ ) [59]. Reprint by permission from John Wiley and sons.

\subsection{Carbon-based electrodes}

Carbon-based electrodes are relatively simple to manufacture and are of low cost and cheap production processes. They have a large electrochemical potential window, low background noise, and less fouling than their metal-based counterparts. Besides this, many biologically relevant analytes are organic compounds and, consequently, generate a better response at carbon-based electrodes [61]. Thus, this kind of electrode has been extensively applied in MCE-EC systems. Several articles present different types of carbon for their integration into microdevices, including pyrolyzed photoresist film (PPF) carbon, carbon fiber $(\mathrm{CF})$, carbon paste $(\mathrm{CP})$, carbon ink $(\mathrm{CI})$, and boron doped diamond (BDD) electrodes. Whereas carbon electrodes are a good choice for detection in microchips made of soft polymers, plastics, or hybrid chips, they have limited stability under high temperature and pressure conditions used for bonding all-glass devices.

\subsubsection{Pyrolyzed photoresist film (PPF) carbon}

PPF carbon is a material which does not present stability issues as the other types of carbon. In other words, PPF electrodes can be manufactured on glass substrates using photolithographic procedures. First, a photoresist is placed in the pattern of the desired 
electrode onto a substrate. Then, the substrate with photoresist is placed in a tube furnace under an inert gas atmosphere under temperatures up to $1100^{\circ} \mathrm{C}$ to produce conducting carbon films (Figure 5).

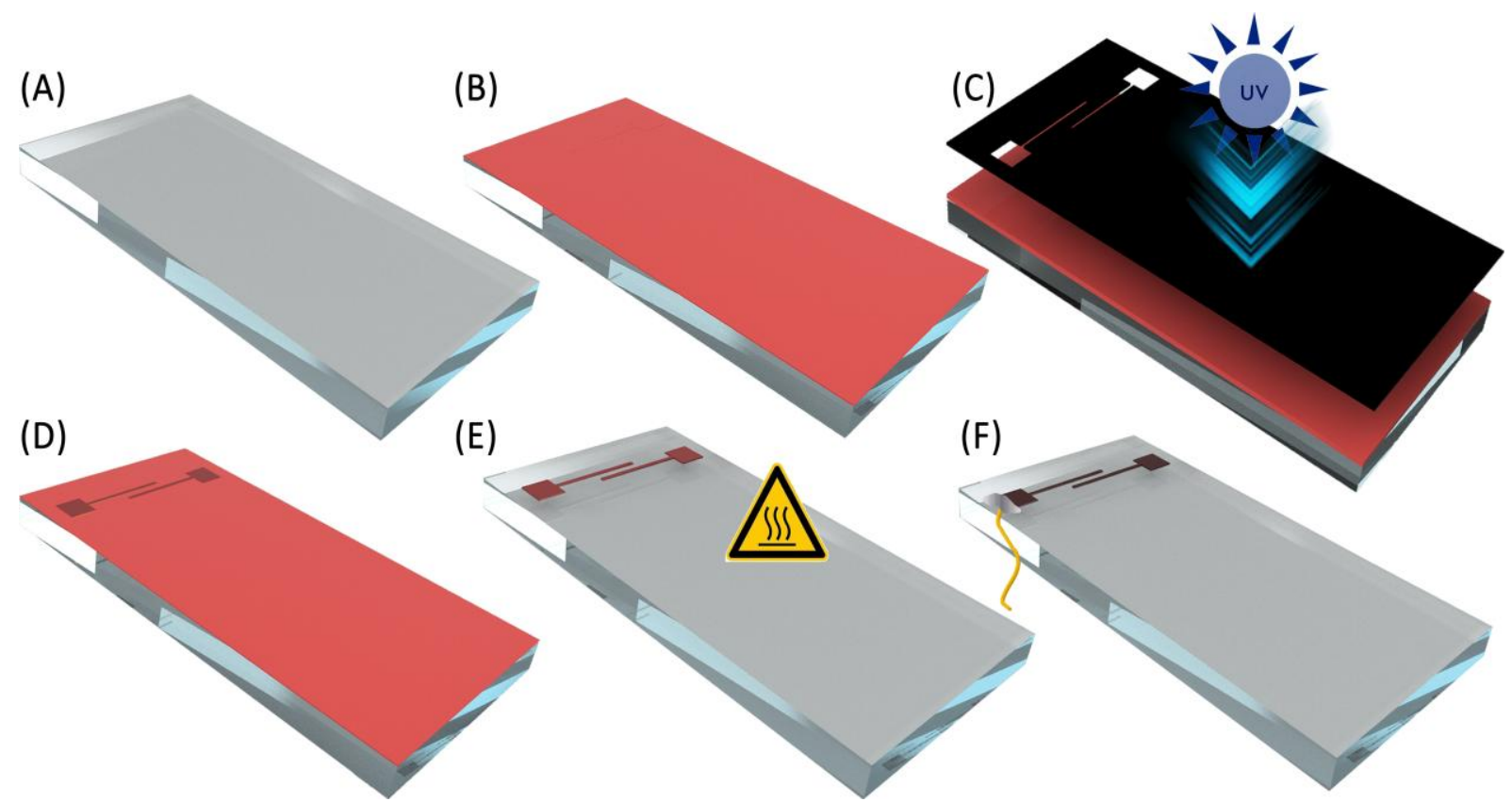

Figure 5. PPF carbon electrode assembly: A. Glass substrate; B. A negative photoresist is deposited on the electrode substrate; C. A mask with desired features is placed over the substrate and is exposed to UV light; D. The substrate is placed in photoresist developer and E. Only the electrode pattern (in photoresist) persists after development; F. Following pyrolysis in a tube furnace, a carbon electrode persists on the substrate. Connections are prepared with silver colloidal and copper wire.

Although PPF is similar in many ways to a smooth version of polished glassy carbon (GC), there are some significant differences which may have substantial electroanalytical consequences, to begin with its extraordinary smoothness, with a RMS (Root Mean Square of a surface measuring microscopic peaks and valleys roughness) of approximately $1-10 \%$ of polished GC [62]. Then, the capacitance and background current are lower than for traditional GC. Merged with the ability to produce patterns on a scale of $10-20 \mu \mathrm{m}$, the near atomic flatness of PPF allows production of novel electrode structures, for instance very thin electrode layers and interdigitated carbon arrays. However, they do have a low oxygen/carbon ratio, leading to slow electron transfer kinetics for some analytes [62]. The physicochemical and electrochemical characterization of PPF carbon electrodes were explored by Ranganathan et al. [62]. The authors studied electron-transfer kinetics of various redox systems comparing PPF surfaces with heat-treated glassy carbon (HTGC) and GC electrodes. Briefly, the PPF provides well-defined, but less reversible behaviour than on HTGC or GC for all the redox systems investigated (Figure 6). 



Figure 6. Voltammetry of $\mathrm{Fe}^{3+} \rho^{2+}$ and dopamine on PPF and HTGC. All electrode surfaces were cleaned with activated carbon in IPA before voltammetry [62]. Reprint by permission from American Chemical Society.

Saylor et al. [63] published two different microchip substrates (PDMS/glass and PDMS/PDMS) employing different microband (33 $\mu \mathrm{m}$ width) electrode materials, PPF and CF electrodes, respectively. The authors monitored DA metabolism in a rat brain slice. The improvements achieved with the use of PPF electrode were higher sensitivity and lower LODs than with CF electrodes, owing to a decrease in background noise. Furthermore, PPF may be fabricated into possibly complex microstructures or in uncommon shapes that are not amenable to polishing. However, since polishing is unnecessary, mass production of PPFbased sensors is possible. Although PPF electrodes have several advantages for MCE-EC systems, other types of carbon electrodes are more indicated for thermoplastic and polymer substrates, for instance $\mathrm{CF}$ electrodes.

\subsubsection{Carbon fiber (CF) electrodes}

CF electrodes are often integrated into MCE systems by placing the fiber into a PDMS substrate taking extreme care not to break the fiber. A channel whose width corresponds to the diameter of the fiber is typically created in a PDMS substrate supported on a glass for increased rigidity. The CF is then placed on the trench created in the bottom layer of the PDMS chip which is perpendicular to the separation channel and pushed into it, taking extreme care not to break the fiber. With the purpose to make connections to the fiber, $\mathrm{a} \mathrm{Cu}$ wire is epoxied onto the glass support, and the fiber and wire are connected by colloidal silver [64]. This approach for inserting the fiber into the trench may be laborious and time consuming. Thereby, alternative methods for integrating CF in microdevices were also described. Cheng et. al. [65] reported the use of carbon fiber nanoelectrodes (CFNE), previously described by the group [66], as EC detector in MCE systems (Figure 7A). To fabricate CFNE, a glass capillary was pulled on the flame to build a tip. A cleaned CF 
connected to a copper wire was inserted from the other end of the glass capillary into the tip with CF protruding from the tip (Figure 7B). The CF was then flame-fuse-sealed in the tip of the glass capillary. The CFNE electrodes were characterized by scanning electron microscopy (SEM) (Figure 7C) and by cyclic voltammetry (CV), linear sweep voltammetry (LSV) and differential pulse voltammetry (DPV) using ferrocyanide as electrochemical probe (Figure 7D). The results showed that the CFNEs have excellent electrochemical behaviour and high sensitivity. The tip of CFNE can be controlled within the range from 100 to $300 \mathrm{~nm}$.

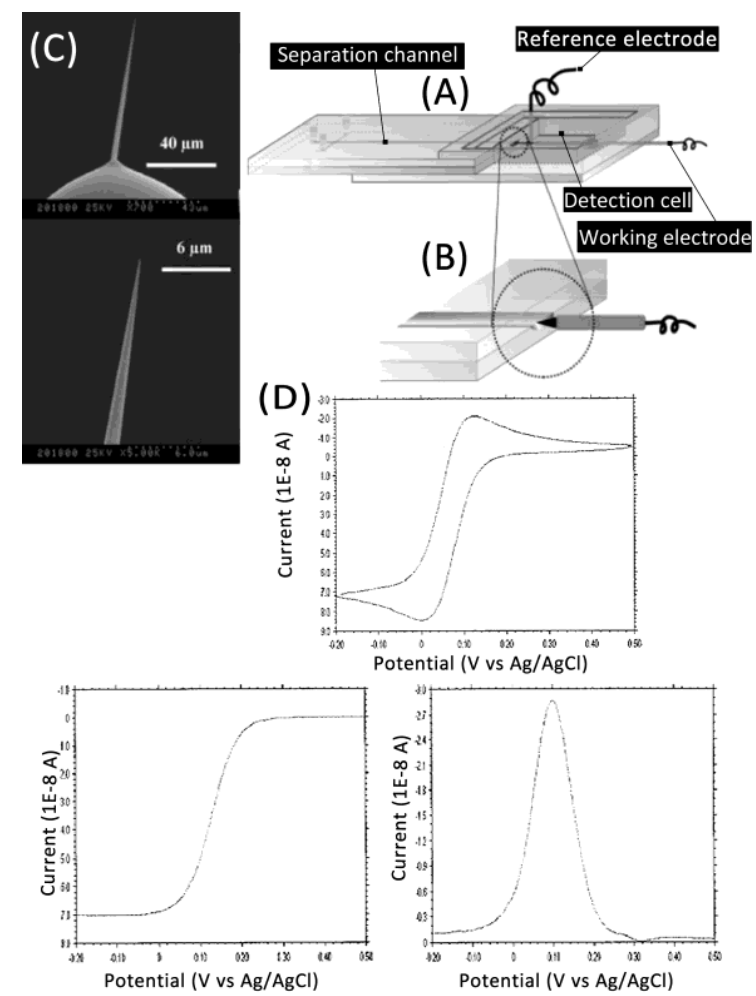

Figure 7. Microfluidic system with CNFE. (A) Configuration of a MCE system with integrated EC detection: (1) sample reservoir; (2) buffer reservoir; (3) sample waste reservoir; (4) separation channel; (5) detection cell; (6) working electrode; (7) RE electrode; and (8) epoxy; (B) Better view of the outlet of the separation channel coupled with CNFE. (C) SEM images of CFNE and tip of a CNFE. (D) Cyclic, linear sweep and differential pulse voltammograms of $1.0 \times$ mM potassium ferricyanide in $0.1 \mathrm{M}$ phosphate buffer solution ( $\mathrm{pH}$ 7.4) obtained with a CFNE; tip diameter, $200 \mathrm{~nm}[65,66]$. Reprint by permission from American Chemical Society and John Wiley and sons.

\subsubsection{Carbon paste/ ink electrodes}

CP electrodes have been employed for many years for EC detection since their introduction by Adams in the 1950s [67]. The first reported use of a CP electrochemical detector for microchip electrophoresis was described by Lunte's group in 2001 [68]. CP electrodes have the benefit to be integrated into more rigid substrates, for instance plastic or glass, while CF may only be placed in the more malleable PDMS.

$\mathrm{CP}$ electrodes are manufactured by building a channel in PDMS, PMMA or glass, where a mixture of a carbon-based material (graphite and carbon nanotubes) is placed with a 
binding agent to produce a working electrode. The binding agent commonly used for integration of CP electrodes is oil, but some studies have described the use of microchip material itself to improve mechanical ruggedness and substrate compatibility. Regel et al. [69] developed integrated graphite/ PMMA composite electrodes with $100 \mu \mathrm{m}$ width into a PMMA substrate. The two parts of the chip were sealed using a solvent-assisted thermal bonding method to form the final MCE-EC device. Recently, Gouyon et al. [70] described the development of screen-printed graphite/ PDMS band electrodes of $30 \mu \mathrm{m}$ width into a PDMS substrate for amperometric detection in MCE systems (Figure 8A). The PDMS was explored by the authors, as this material could be used as a sealing agent between the carbon composite electrode and a microfluidic system made of the same polymer, owing to its physico-chemical properties, such as covalent bonding ability after plasma surface treatment and elasticity. CV (Figure 8B) and SEM (Figure 8C) were used to characterize the microband carbon composite electrodes. 

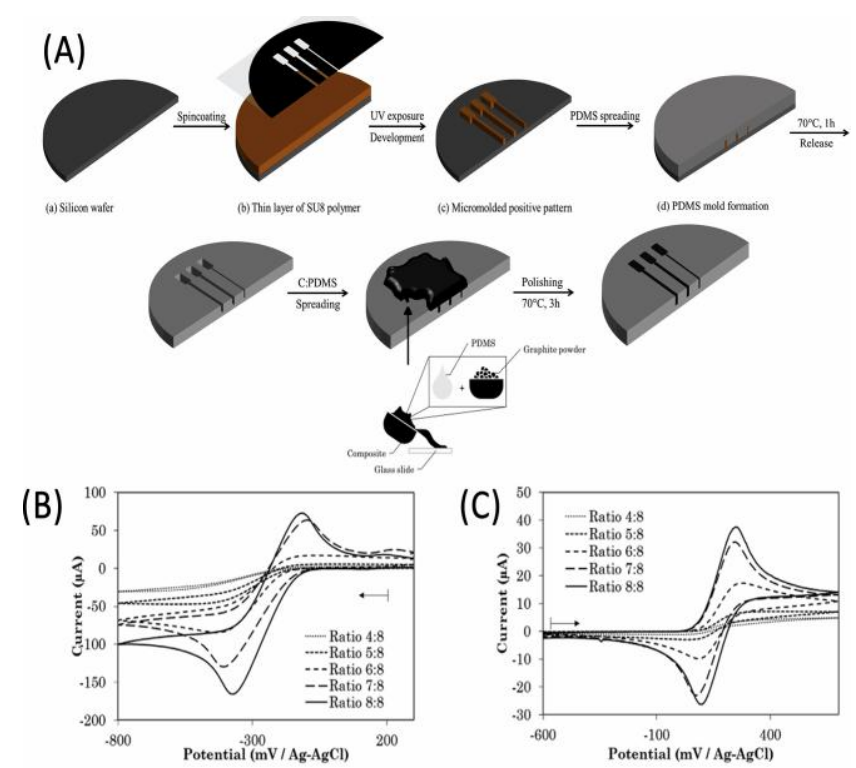

(D)
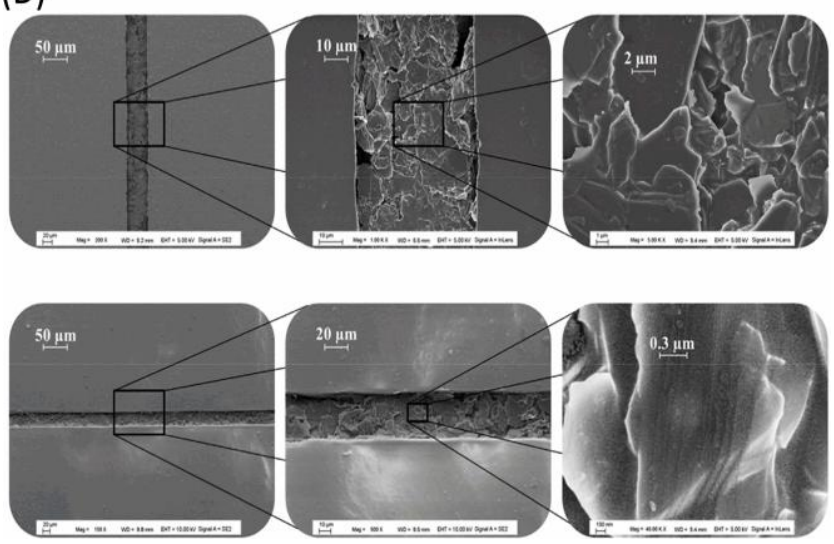

Figure 8. Development of a screen-printed electrode and its characterization. (A) Scheme of the fabrication of the 3electrodes setup made of C/ PDMS mix. (B) Electrochemical characterization by cyclic voltammetry on C/PDMS electrodes of (B) $5 \mathrm{mM} \mathrm{Ru}\left(\mathrm{NH}_{3}\right)_{6}{ }^{3+}$ and (C) $1 \mathrm{mM} \mathrm{FcMeOH}$. WE $=$ C/PDMS 8/8 (w/w) circular, pseudo- $\mathrm{RE}=\mathrm{Ag}-\mathrm{AgCl}$ wire, $\mathrm{CE}=\mathrm{Pt}$ wire. Scan rate $25 \mathrm{mV} \mathrm{s}^{-1}$. (D) SEM images of C/PDMS electrode [70]. Reprint by permission from Elsevier.

The CP electrodes may also be manufactured by a commercial printer or a screenprinting technique. The microchip design is deposited on a screen of polyester or other fine mesh, with blank areas coated with an impermeable substance or on a substrate with pattern trench. The paste or ink is pressed into the mesh or substrate with a squeegee and onto the surface to be printed. The excess may be removed by pressing or/and removing a piece of Scotch ${ }^{\circledR}$ tape over the electrodes. Nowadays, this microfabrication technology is wellestablished for mass production of thick film electrodes. In addition, silver electrodes and CI electrodes also may be produced using this technique, that is helpful to obtain pseudo-RE and auxiliary electrodes (AE) [71].

CI electrodes are popular materials for commercial versions of MCE-EC systems. As discussed before, these electrodes may be fabricated by screen-printing on PDMS [72], glass, or epoxy [59] substrates. With the purpose to facilitate the electrical connection to CI 
electrodes, some groups previously integrated a metal electrode connector in the device by sputtering and evaporation. The micromolding structure made by soft lithography techniques is aligned and reversibly sealed over the metal connectors, and an ink mixture is aspirated through the channels. Mecker and Martin [73] reported this approach to fabricate a $13 \mu \mathrm{m}$ length microband CI electrode with Pd connectors for amperometric detection in microdialysis sampling and microchip electrophoresis device. Recently, a novel method to fabricate screen printed electrodes was reported by Petroni et al. [74]. Briefly, two pieces of adhesive tape were pasted onto an PMMA substrate, at a distance delimiting the electrode width. Once established the electrode region with the adhesive tapes, the carbon electrode was drawn onto the substrate and subsequently, a layer of CI was gently spread over the delimited area. Lastly, the electrode was kept at room temperature to dry, leaving just the CI over the acrylic substrate (Figure 9.1). The authors monitored the thickness of the sample by polishing SEM images of the carbon electrode surface having various thicknesses that are shown (1.15 $4.33 \mu \mathrm{m})$ in Figure 9.2 (A-D). Since the CI deposition and electrode polishing steps are manually performed, the electrode reproducibility can be a problem. Using the proposed method, the thickness layer was $3.18 \pm 0.51 \mu \mathrm{m}$ with an RSD of $11.6 \%(n=5)$. The authors characterized the electrodes by performing hydrodynamic voltammograms to set up an optimum detection potential value (Figure 9.2.E) for nitrite and ascorbate. These novel electrodes provided stable background current and suitable $\mathrm{S} / \mathrm{N}$ ratio. 


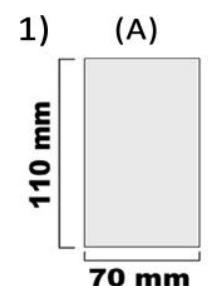

(B)

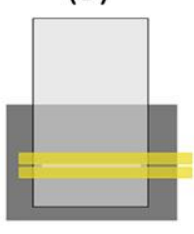

(F)
(C)

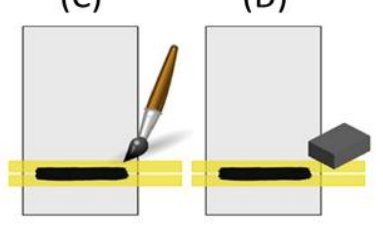

(G)

( $\mathrm{H})$

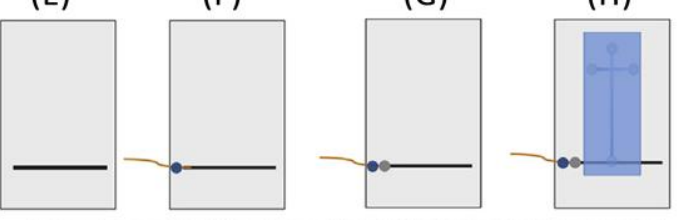

2)
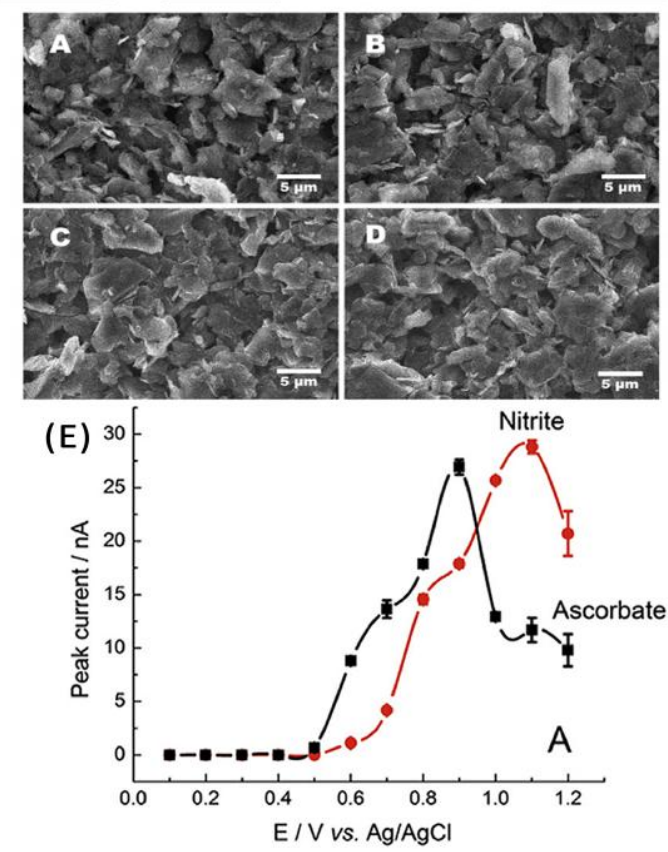

Figure 9. Scheme of the electrode microfabrication process: 1A substrate cleaning; 1B adhesive tapes to delimit the electrode area (an office paper mask was used as reference to define the electrode area); 1C handmade deposition of homemade carbon ink over between the adhesive tape; 1D electrode surface polishing; 1E. revealed electrode through removal of adhesive tape; $\mathbf{1 F}$ electrical contact made by a copper wire attached with epoxy resin; $\mathbf{1 G}$ colloidal silver glue application to provide electrical contact between the copper wire and the electrode; $1 \mathbf{H}$ alignment of PDMS device over the substrate containing the electrode. 2. SEM images obtained from electrode surfaces with different thickness: (A) $1.15 \mu \mathrm{m}$; (B) 2.21 $\mu \mathrm{m}$; (C) $3.18 \mu \mathrm{m}$ and (D) $4.33 \mu \mathrm{m}$. 2E hydrodynamic voltammograms constructed from electropherograms recorded at different detection potentials. Experimental conditions: $5 \mathrm{mM}$ phosphate buffer ( $\mathrm{pH}$ 6.85) containing $200 \mu \mathrm{M} \mathrm{CTAB}$; injection voltage: $-700 \mathrm{~V}$ for $6 \mathrm{~s}$; separation voltage: $-1200 \mathrm{~V}$ [74]. Reprint by permission from Elsevier.

\subsubsection{Pencil electrodes}

Pencil drawing is the simplest and lowest-cost method for the rapid production of carbon-based electrodes on paper. Chagas et. al. [75] published, for the first time, the fabrication of a pencil drawn electrode (PDE) on paper platforms to accomplish $\mathrm{C}^{4} \mathrm{D}$ detection in a PMMA electrophoresis chips. The electrodes bands $(2 \times 2 \mathrm{~mm})$ were printed on the paper substrate to delimit the electrode area. Next, PDEs were drawn on the top face of the printed area by a pencil. The feasibility of the proposed device was shown with the separation of inorganic cations in tear samples. After that, the authors reported the use of PDEs on a paper- 
based MCE-C ${ }^{4} \mathrm{D}$ device for separation of bovine serum albumin and creatinine, main biomarkers in the detection of kidney disease. The authors successfully provided microfluidic devices of extremely low cost (less than $\$ 0.10$ ) and easy to manufacture, especially to integrate the sensitive electrodes [76].

\subsubsection{Boron-doped diamond (BDD) electrodes}

The benefits of BDD electrode material for MCE-EC systems are their ruggedness and reproducibility, offering less capacitive currents, a rapid electron transfer kinetics and a wide electrochemical potential window. These electrodes are achieved by depositing a thin film of BDD on silicon wafers by a high-pressure plasma-assisted chemical vapor deposition system with both boron and carbon sources. Subsequently, chemical etching is used to dissolve the silicon wafer substrate to produce a free-standing diamond thin film. This film can then be glued to the substrate with an adhesive tape. Quick-setting nonconductive epoxy may be used for shaping of the WE area [77]. Wang et al. [78] highlighted the attractive behaviour and advantages of BDD electrode detector for a MCE system in 2003. The authors compared critically the performance of BDD electrode $(6.0 \times 0.3 \mathrm{~mm})$ in band-shape to a commonly used screen-printed electrode in the same operational conditions (Figure 10). One advantage is the reduced fouling offered by the electrode, which reflects the negligible adsorption of organic compounds at the BDD surface. The BDD detector displays higher stability (Figure 10A), higher sensitivity (Figure 10B) and lower noise level (Figure 10C) for microchip measurements of TNT (2,4,6- trinitrotoluene) response. 
(A)



(B)

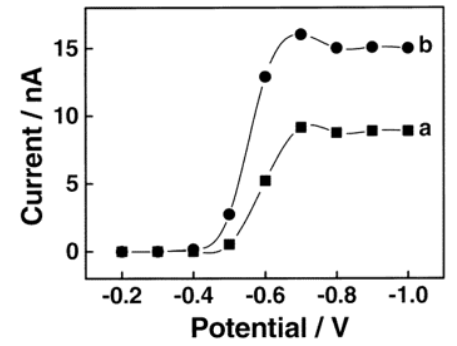

(C)

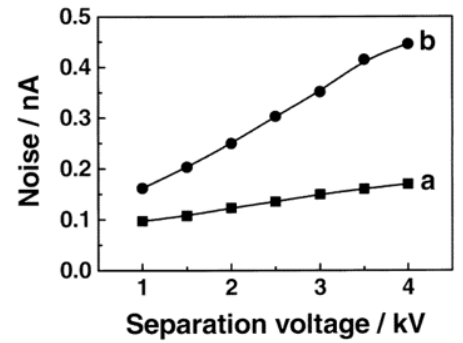

Figure 10. Comparison of the performances for BDD and screen-printed electrodes. (A) Reproducibility of the detection intensity for successive flow injection measurements of $22 \mu \mathrm{M}$ TNT using (a) BDD and (b) screen printed carbon electrodes. (B) Hydrodynamic voltammograms for $66 \mu \mathrm{M}$ TNT at (a) screen printed and (b) BDD electrodes. (C) Impact of separation voltage on the baseline noise for (a) BDD and (b) screen printed carbon electrodes [78]. Reprint by permission from American Chemical Society.

\subsection{Nanostructured and/or chemically modified electrodes}

Modification of electrode surface is often employed to increase the electronic transfer rate, amplify the current signals and/ or improve the selectivity of MCE-EC analysis toward specific analytes [79]. EC deposition is a technique widely used for modification of electrodes in microdevices using $\mathrm{CV}$. The main advantage of this strategy is that electrodeposition may be conducted into the microchip, reducing the number of steps. The electrode is modified by immersion in a metal salt solution, which is electrochemically reduced on the electrode surface. In the literature, the readers may find several reviews dedicated to electrochemical detectors based on nanomaterials $[80,81]$ which cover the impact of nanomaterials to enhance detection performance in CE, MCE and microfluidic systems and their application. In this section, we address the novelty behind the fabrication process and its impact on the analytical performances.

A gold nanoparticle-modified indium tin oxide microelectrode for amperometric detection in MCE was developed by Zhu et al. [82]. The authors optimized the deposition conditions in terms of deposition cycles, deposition potential range and scan rate, as well as 
concentration of the electrolyte to obtain high particle density s for the fabrication of a highquality sensor.

Platinization is a popular electrode modification, consisting in an EC deposition of platinum black nanoparticles on a platinum or a carbon WE. This type of modification improves the electron transfer kinetics for small molecules, for instance reactive and oxygen species, and increases the surface area of the electrode. Comparing with bare Pt electrodes, platinum black (Pt-black) can provide current magnification about 3 times in case of hydrogen peroxide and 6 times for $\mathrm{NO}_{2}{ }^{-}$. Pt-black is commonly used for studies involving hydrogen peroxide and nitric oxide analyses, also monitoring reactive species from cells in MCE-EC systems and in miniaturized sensors $[83,84]$.

A material which has become popular for modified electrodes is reduced graphene oxide. This modification with graphene may be achieved by electrochemical reduction of graphene oxide $(\mathrm{GO})$ over the electrode surface with an electrodeposition process in which the oxygenated functional groups are removed from GO sheets. Electrode modification with GO does not require any specific chemical reagent and is accomplished by the electron transfer between GO and the working electrode. This method avoids the use of harmful reducing agents such as hydrazine and prevents the formation of intermediates. We may find a few examples of the use of reduced graphene oxide for MCE-EC. Chua and Pumera [85] reported the performance of reduced graphene on GC electrodes to detect DA and CA. Electrochemically reduced graphene was shown to exhibit higher peak resolution and greater separation efficiencies than thermally and chemically reduced graphene, with two-fold increment as compared to the bare GC. More recently, Lucca et al. [86] described, for the first time, the modification of Pt electrodes integrated into a commercial MCE system by deposition of reduced GO for the selective amperometric detection of ascorbic acid in a commercial medicine sample.

Single-walled (SW) and multi-walled (MW) carbon nanotube (CNT) electrodes have also been widely employed in EC detection because of their outstanding features such as large surface area, reduced surface fouling, and good electron transfer kinetics, which allows to enhance the analytical features of the analyses (repeatability, selectivity, sensitivity). The surface modification of carbon nanomaterial-based electrodes has been performed by casting a drop containing a carbon nanomaterial dispersion on a solid electrode surface. This method has an issue with the deposited film, which can be mechanically fragile and the presented signal is dependent on two carbon sources, the carbon nanomaterial and the commercial transducer [87]. Some new strategies have been reported such as the use of the carbon 
nanomaterial as exclusive material to improve the analytical response and allow reliable studies of the pure nanomaterial. For instance, Martin and Escarpa [88] developed SWCNT press-transferred, as a unique conductive material, for EC detection in MCE. The new carbon nanomaterial is produced by filtration of SWCNTs on a Teflon filter. The filtered nanomaterial is homogeneously press-transferred on a nonconductive PMMA substrate, where SW carbon nanotube acts as exclusive transducers. The authors explored the excellent properties of carbon nanomaterials for screening melatonin, tryptophan, and serotonin.

\section{Electrochemical detection within MCE}

\subsection{Amperometric detection mode}

Generally, a basic three-electrode (working, auxiliary and reference) system has been used, but it can also be implemented in a two-electrode (working and reference) way when using working ultramicroelectrodes. Even though amperometry is the most frequently used electrochemical method in microfluidic devices, pronounced shortcomings limit its applications. First, there is a necessity to improve the reproducibility of the surface of the WE and the reproducibility of its position and alignment within the separation channel. Second, the high voltage needed for the separation step induces interferences with the low electrical field used for the amperometric detection, compromising the obtained results. Thus, different strategies to prevent or minimize the interaction of the separation electric field with the WE are required. The three major electrode configurations are in-, end-, and off-channel electrode alignment.

\subsubsection{Off-channel detection}

In this configuration, the current associated with the high separation voltage is minimized by a fracture (often called a decoupler or joint) which is made in the capillary and grounded prior to the detection area. In other words, the WE is isolated from the separation voltage. Briefly, the decoupler is manufactured by a fracture of the separation channel nearby to its end. Then, this region is immobilized in order to increase the mechanical strength of the device. A porous membrane is positioned along the fracture, enabling the conduction of the current and finally, this device is placed in contact with the grounding separation electrode. There are several materials which can be used as membrane: Nafion ${ }^{\circledR}$, porous glass, graphite, cellulose acetate and other polymers. In the off-channel alignment, the WE is placed inside the channel and the separation electric field $(\vec{E})$ is efficiently moved to ground by a 
decoupler, promoting the electrical isolation of the detector from the separation voltage. A field-free region is created where analytes are pushed straight to the WE by the residual hydrodynamic flow produced from the EOF generated up-stream the decoupler. As a result, this leads to low background noise and no voltage fluctuations in the WE owing to the separation voltage, which can result in low LODs. However, this configuration requires a strong EOF to "push" the analytes to the detection electrode. Also the WE and the decoupler should be maintained very close to each other to avoid signal broadening and loss of resolution (Figure 11).

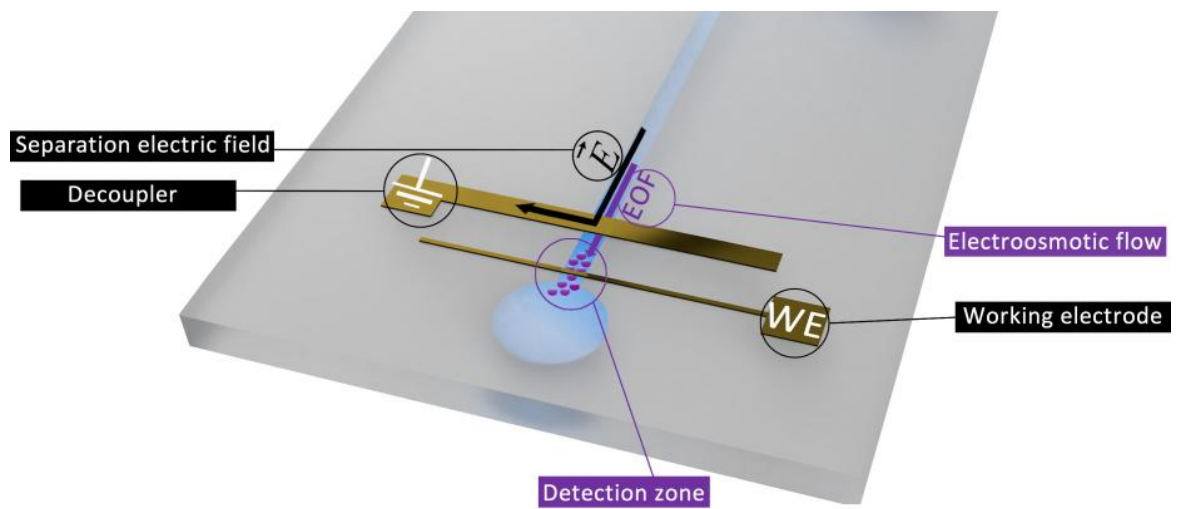

Figure 11. Electrode off-channel alignment used in MCE-EC with a single working electrode. The separation field $(\vec{E})$ is moved toward the ground by a decoupler. The analytes are carried toward the WE by hydrodynamic flow produced from the EOF.

The main challenge to integrate a decoupler into an MCE-EC system is that the decoupler and the WE are typically composed of different materials which may require different fabrication methods. The disadvantage of this alignment is the generation of gas at the decoupler owing to the production of hydrogen gas at the cathode or oxidation of water at the anode, depending on the applied polarity, leading to the formation of bubbles inside the channel and consequently disturbing the separation. Metal band electrodes, such as Pd [89] and Pt [90], are widely employed as decoupler, as they can absorb the hydrogen gas produced at the cathode, minimizing bubble formation. However, no study has yet reported the existence of decouplers for a reversed polarity separation, in which the electrode material would absorb oxygen gas in MCE-EC systems.

Beyond the metal-based decouplers, cellulose acetate decouplers have been described for MCE-EC. This approach was presented by Osbourn and Lunte [91]. This procedure consists in a fracture which is created within the microchannel, then covered by an ionpermeable membrane, for instance Nafion ${ }^{\circledR}$ or cellulose acetate, and positioned in the ground reservoir. Afterwards, the authors described the use of cellulose acetate decoupler which was 
placed over a part of the separation channel which has been etched to provide an ion path (Figure 12A). Using this configuration, noise values as a function of separation current for the designed decoupler were evaluated and low background noise (arising from the isolation of the detector cell from separation current) up to $60 \mu \mathrm{A}$ was obtained (Figure 12B). The authors reported on operational ability of the MCE device to perform analyses at extremely high fields strengths, enabling higher resolution in ultrafast separations (30 s). In this study, the application of $700 \mathrm{~V} \mathrm{~cm}^{-1}$ did not affect the detector (noise levels at or below $1 \mathrm{pA}$ ), resulting in LOD of $25 \mathrm{nM}$ for DA with a CF electrode, which is a low LOD value for EC detection within MCE system (Figure 12C). The separation current is grounded through the fracture covered with this membrane. The targeted compounds are pushed from the decoupler (fracture) to the WE by the EOF generated in the separation part of the channel [92].
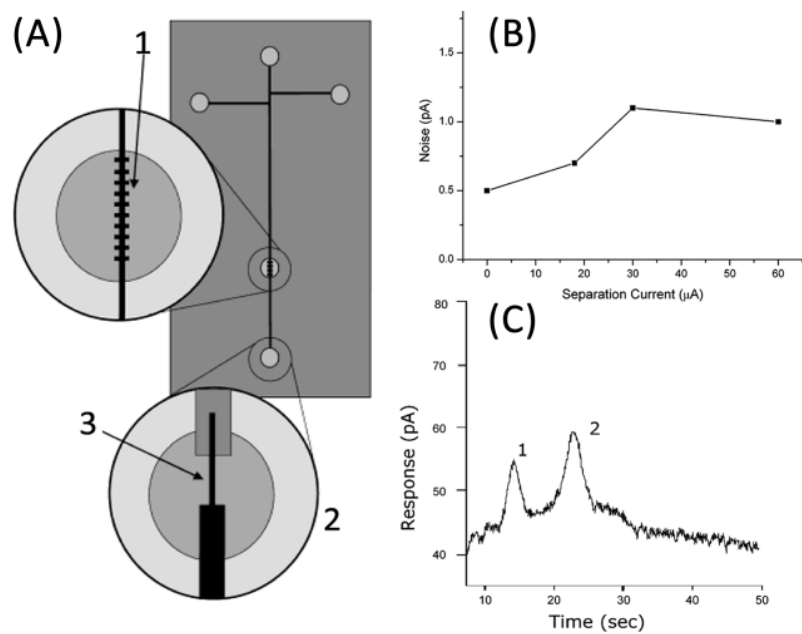

Figure 12. (A) Microchip with laser-etched decoupler layout. (A): (1) decoupler holes, (2) detector reservoir, and (3) CF electrode. (B) Noise values as function of separation current for the laser-etched decoupler. (C) Electropherogram of the injection of (1) $82 \mathrm{nM}$ DA and (2) $500 \mathrm{nM}$ hydroquinone in the MCE-EC system [92]. Reprint by permission from American Chemical Society.

\subsubsection{In-channel detection}

Martin and co-workers [93] reported on the in-channel detection mode. This approach allows the analytes migrating over the electrode while they are in the separation channel, minimizing analytes diffusion and resulting in high separation efficiencies, high sensitivities, and well-defined peaks. However, this detection mode must have an isolation of the high separation voltage from that required for the detection at the WE, which may be achieved by using an electrically isolated potentiostat. Indeed, when the electrode is positioned within the separation field ( $\vec{E}$ ) (Figure 13), there may be both potential shifts and increase of noise due to the separation voltage fluctuations. This results in increased background noise at the detector and high LODs, even if the separation efficiency is improved. 


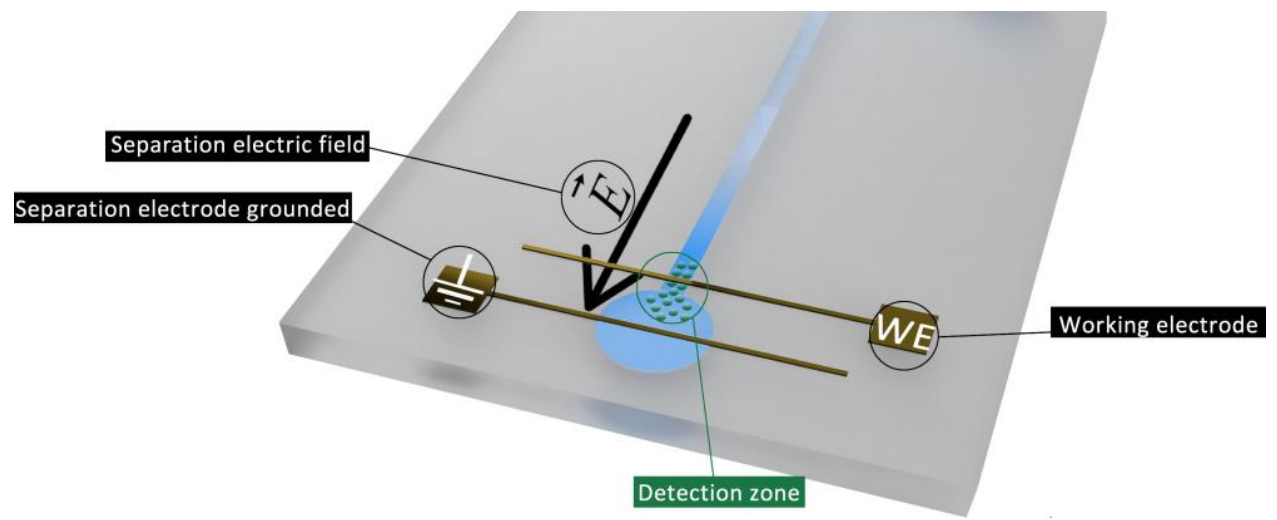

Figure 13. Electrode in-channel alignment used in MCE-EC with a single working electrode. The separation field $(\vec{E})$ is moved toward the ground electrode. The WE electrode is placed between separation electrodes.

To overcome the LOD issue and improve the performance of the amperometric detection, Chen and Hahn [94] published a dual electrode/ dual in-channel microchip configuration to subtract the background signal. Both electrodes, WE and RE are positioned at the same distance from the outlets of two identical channels, one is used as a separation channel and the second is used as a "reference" channel. The symmetry of dual channel microchips allows the electrodes to experience the same electric potentials and fluctuations, and thus the interferences are cancelled out during the measurement of the current between the two electrode set-ups (Figure 14).

1)

A

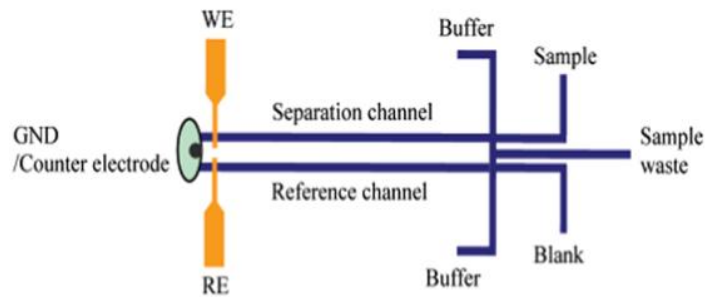

B

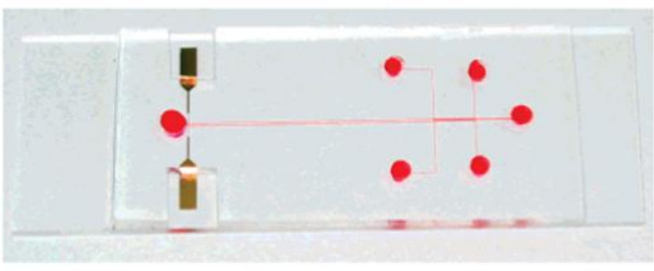

2)
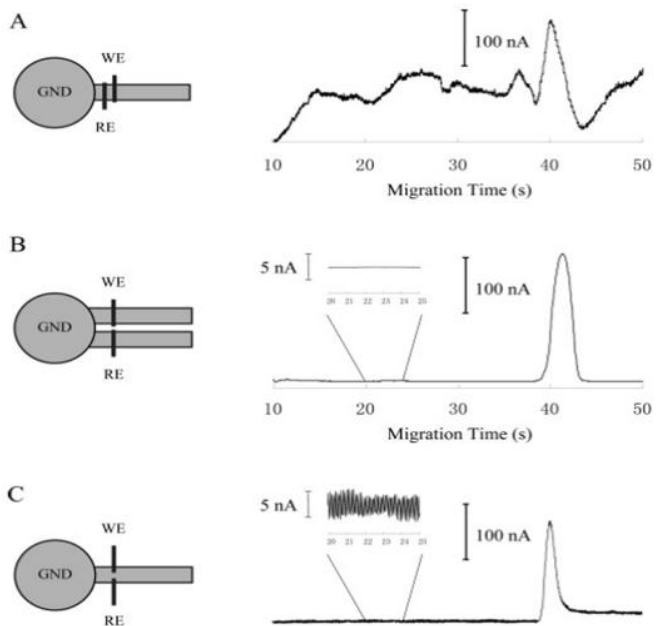



Figure 14. 1A. Scheme of a MCE-EC in dual electrodes in-channel configuration. 1B. Photograph of the real microchip. Electropherograms of $5 \mathrm{mM}$ dopamine: 2A. in a single in-channel configuration; $2 \mathbf{B}$ in a dual in-channel configuration; 2C. in a single in-channel, head- to-head WE-RE configuration [94]. Reprint by permission from American Chemical Society.

\subsubsection{End-channel detection}

End-channel configuration was the first developed configuration and is the most common alignment for MCE-EC systems. This alignment explores the strategy of placing the WE at the exit of the separation channel, 5-20 $\mu \mathrm{m}$ away from the outlet end (Figure 15). By 
doing so, the influence of the separation electric field on the electrochemical detection is avoided. This configuration is predominantly developed now because of its ease of microfabrication but also electrode accessibility and cleaning. But this alignment, in which the analytes diffuse into the waste reservoir as they exit the channel before being detected, induces a significant broadening of the signals and asymmetry of the peak shapes, which leads to loss of separation efficiency and reduction in sensitivity.

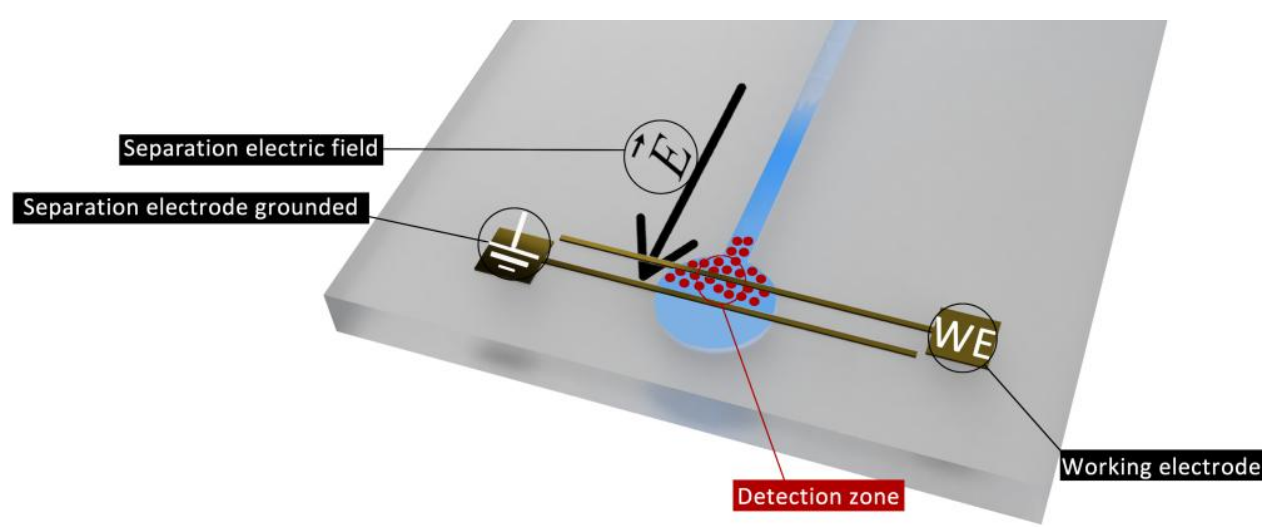

Figure 15. Electrode end-channel alignment in MCE-EC with a single working electrode. The analytes are widespread into the waste reservoir leaded by separation current. The separation field $(\vec{E})$ is moved toward the ground electrode.

Ertl et al.[95] developed an integrated sheath-flow channel to be placed at $30^{\circ}$ angles relative to the separation channel (Figure 16A) to focus the fluid stream over the middle of the WE (Figure 16B). Consequently, the sheath-flow subtracted the influence of separation voltages on end-column detection while preserving optimum performance. The novel device consists of an upper glass substrate containing the etched fluidic elements (separation, injection, and sheath-flow channels) and a lower glass with the metal electrodes integrated by sputtering. The authors used catechol for the evaluation of the performance of this sheathflow EC detector. This allowed obtaining efficient detection of the targeted analyte (sensitivity $\left.=0.18 \mathrm{nA} \mu \mathrm{M}^{-1}\right)$ and low background-noise level $(\mathrm{LOD}=4.1 \mu \mathrm{M})$ at distance of up to $250 \mu \mathrm{m}$ from the separation channel outlet (Figure 16C). In addition, the analysis of CA as model substance evidenced a linear detector response in the 10 to $500 \mu \mathrm{M}$ range (Figure 16D). The absence of sheath-flow support resulted in a significantly low ( 90\%) and broader signal peaks. 

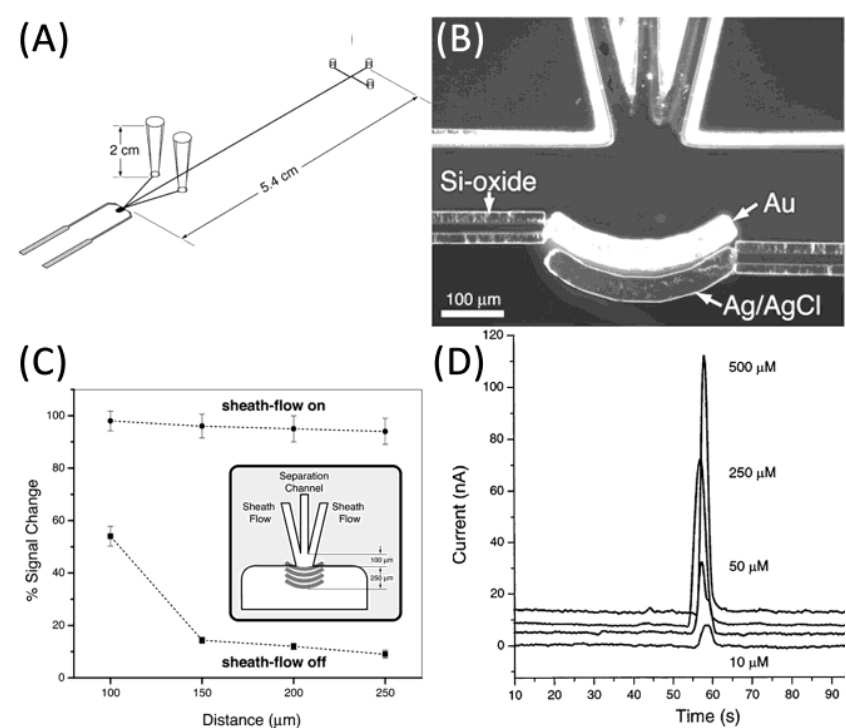

Figure 16. The MCE-EC chip with sheath-flow channel (A) Exploded view of a separate channel with integrated sheath-flow channels. (B) Electrodes at the detection region visualized under a microscope. (C) Catechol separations presented as relative (\%) signal changing as a function of electrode distance from the separation channel $(100,150,200$, and $250 \mu \mathrm{m})$ calculated in the absence and presence of sheath-flow support. (D) Catechol linear range $(500,250,50$, and $10 \mu \mathrm{M})$ provided by $3.5-\mu \mathrm{m}-$ tall gold-plated WE placed $250 \mu \mathrm{m}$ from the separation channel exit [95]. Reprint by permission from American Chemical Society.

More recently, Guan and Henry[96] reported the implementation of a bubble cell at the detection zone to increase the exposed WE surface area to effectively dissipate the separation field. With this approach the authors improved detection sensitivity and decreased LODs compared with a system without a capillary expansion.

It should be noted that the end-column electrochemical detector can be manufactured in a wall-jet configuration; an electrode having an area of several $\mathrm{mm}^{2}$ is being placed opposite to the channel [97]. The wall-jet macroelectrode is easily exchangeable, allowing fast and convenient replacement if passivated. However, the dependence of the separation efficiency upon the detection potential wall-jet macroelectrode was an unexplored subject for application studies. Indeed, there was no article dealing with the fundamental issue until Pumera et al. [98] reported on the study of the EC response of a wall-jet detector for microchip electrophoresis. The authors demonstrated that MCE-EC in wall-jet operates in the coulometric mode, also they demonstrated how the detection potential strongly impacts the resolution of the signals.

\subsection{Conductimetric detection}

Microfluidic devices with electrochemical detection have been mostly based on amperometric mode due to its high sensitivity. However, this approach is limited to the detection of electroactive species. Conductimetry is a relevant complementary approach since it is a universal detection principle, applicable to charge species. Furthermore, conductivity 
detection remains a direct method for sensing small inorganic and organic ions which lack native fluorescence, strong chromophores, or functional groups for derivatization. In these detection systems, usually background electrolytes exhibit a comparatively lower specific conductance compared to those of the target compounds. Nevertheless, high concentration of background electrolytes is required to reduce electro-dispersion effect in MCE. This conductometric detection may be accomplished by either direct contact of the solution with the electrodes (Figure 17A) or contactless method (Figure 17B) which requires capacitivelycoupled devices applying high frequencies.



Figure 17. Comparison between (A) contact and (B) contactless conductivity detection and the usual placement of the electrodes in each detection mode $[99,100]$. Reprint by permission from Elsevier and Royal Society of Chemistry.

\subsubsection{Contact conductivity detection}

The drawbacks of this detection mode are (i) unwanted electrochemical reactions at the electrodes, (ii) fouling of the detection electrodes and (iii) formation of bubbles. In order to avoid them, the authors commonly perform separation with low electric fields. Shadpour et al. [101] employed $90 \mathrm{~V} \mathrm{~cm}^{-1}$ separation field, reduced the distance between the electrodes and minimized their size in a 16-channel polycarbonate (PC) MCE device. The gold sensor array (microbands $60 \mu \mathrm{m}$ ) was lithographically patterned onto a PC cover plate before its thermal bonding on the fluidic network. Even though the contact conductivity sensor array was successfully developed with simultaneous detection of different samples, the LOD for this sensor array was poorer than previous publication using conductivity detection. In order to overcome these limitations and consequently improve compatibility between conductivity detection and microchip, without using current decouplers, a novel bubble cell detection zone (Figure 18A) was designed by Noblitt and Henry[102] in a PDMS microchip with gold-plated tungsten electrodes. The group evaluated the separation of inorganics anions with and without bubble cell (Figure 18B). The obtained results demonstrated that the bubble cell has a 
minimal effect on the separation efficiency, and it decreases the separation field in the conductivity region reducing the voltage drop between the detection electrodes. So, this novelty allowed the use of high separation voltage $\left(600 \mathrm{Vcm}^{-1}\right)$, with reduced background noise and short analysis time (Figure 18C).

(A)

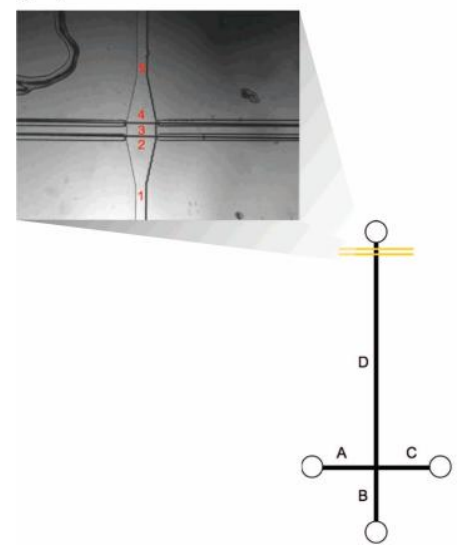

(B)
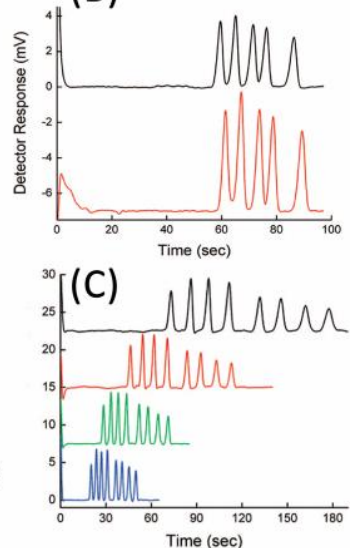

Figure 18. Microchip with amplified detection by a bubble cell. (A) Bubble cell, 3-fold larger than the separation channel. (B) Electropherograms of $25 \mu \mathrm{M}$ chloride, nitrate, perchlorate, chlorate, and hexafluorophosphate (from left to right), using a device without the bubble cell (top) and with a bubble cell (3x the channel size) (bottom). (C) Separation of $50 \mu \mathrm{M}$ anions using a device with a bubble cell at the following separation fields and injection times (top to bottom): $-125 \mathrm{~V} / \mathrm{cm}$ with $2.2 \mathrm{~s}$, $200 \mathrm{~V} / \mathrm{cm}$ with $1.7 \mathrm{~s},-325 \mathrm{~V} / \mathrm{cm}$ with $1.5 \mathrm{~s}$, and $-450 \mathrm{~V} / \mathrm{cm}$ with $1.2 \mathrm{~s}$ [102]. Reprint by permission from American Chemical Society.

\subsubsection{Capacitively-coupled contactless conductivity detection}

In 2001, Guijt et al. [27] reported the first article on contactless conductivity detector (CCD) for microfluidics. The glass MCE was formed by an etched channel and integrated four titanium electrodes covered with a dielectric layer composed by silicon carbide ( $\mathrm{SiC})$. All four electrodes are $106 \mu \mathrm{m}$ long, the two inner electrodes are $30 \mu \mathrm{m}$ wide, the outer electrodes $25 \mu \mathrm{m}$. Unsuccessfully, SiC coating stability was limited to low separation fields $\left(50 \mathrm{~V} \mathrm{~cm}^{-1}\right)$, leading to long analysis times and band broadening. Some improvements of the design were then accomplished by the same authors, allowing for higher separation voltages (at least 3fold) [103]. Tůma et al. proposed a new design for electrodes, easier to achieve, and showed that CCD electrodes for CE do not need to be tubular: they can be fabricated in other shapes without noticeable influence on the CCD performance [104]. This was an important step to move forward manufacturing planar electrodes. A microchip with integrated CCD was reported by Pumera et al. [105] who placed two planar aluminium foil strips electrodes which were fixed onto PMMA cover plate of a microchip using a common epoxy.

Currently, CCD is well known as capacitively-coupled contactless conductivity detection $\left(C^{4} D\right)$. The electrodes are placed outside or near to the channel instead of being inside, leading to efficient isolation from high electric separation fields, easy replacement of 
the separation channel or capillary and alignment of electrodes. Kuban and Hauser [106] reported a PMMA-MCE with copper electrodes to supervise effects of the cell geometry and operating parameters on $\mathrm{C}^{4} \mathrm{D}$ detection within MCE-EC system. The authors used inorganic cations to demonstrate that sensitivity and separation efficiency can be improved by applying lower frequency, high excitation voltage, short and narrow electrodes arranged in an antiparallel configuration and separated by a minimal gap in the $\mathrm{C}^{4} \mathrm{D}$ detection area.

More recently, novel approaches have been published describing microfluidic devices with integrated electrodes for $\mathrm{C}^{4} \mathrm{D}$ detection using emerging materials. Duarte et. al. [107] reported the use of ionic $\mathrm{KCl}$ solutions as sensing electrodes for $\mathrm{C}^{4} \mathrm{D}$ detection in PDMSbased MCE devices. Initially, two detection channels were engraved in parallel orientation onto a PMMA substrate and sealed with a thin adhesive membrane. The separation channels were fabricated in PDMS by soft lithography and reversibly sealed against the PMMA with a polymeric adhesive intermediary membrane (Figure 19A). The authors achieved electrophoretic separations of cationic species with good resolution while avoiding laborious schemes to integrate electrodes, such as metal deposition or encapsulated electrodes (Figure 19B). The results achieved for the $\mathrm{C}^{4} \mathrm{D}$ with liquid electrodes $(\mathrm{KCl}$ solution $2 \mathrm{M})$ settle with the creative and simple electrical model. 

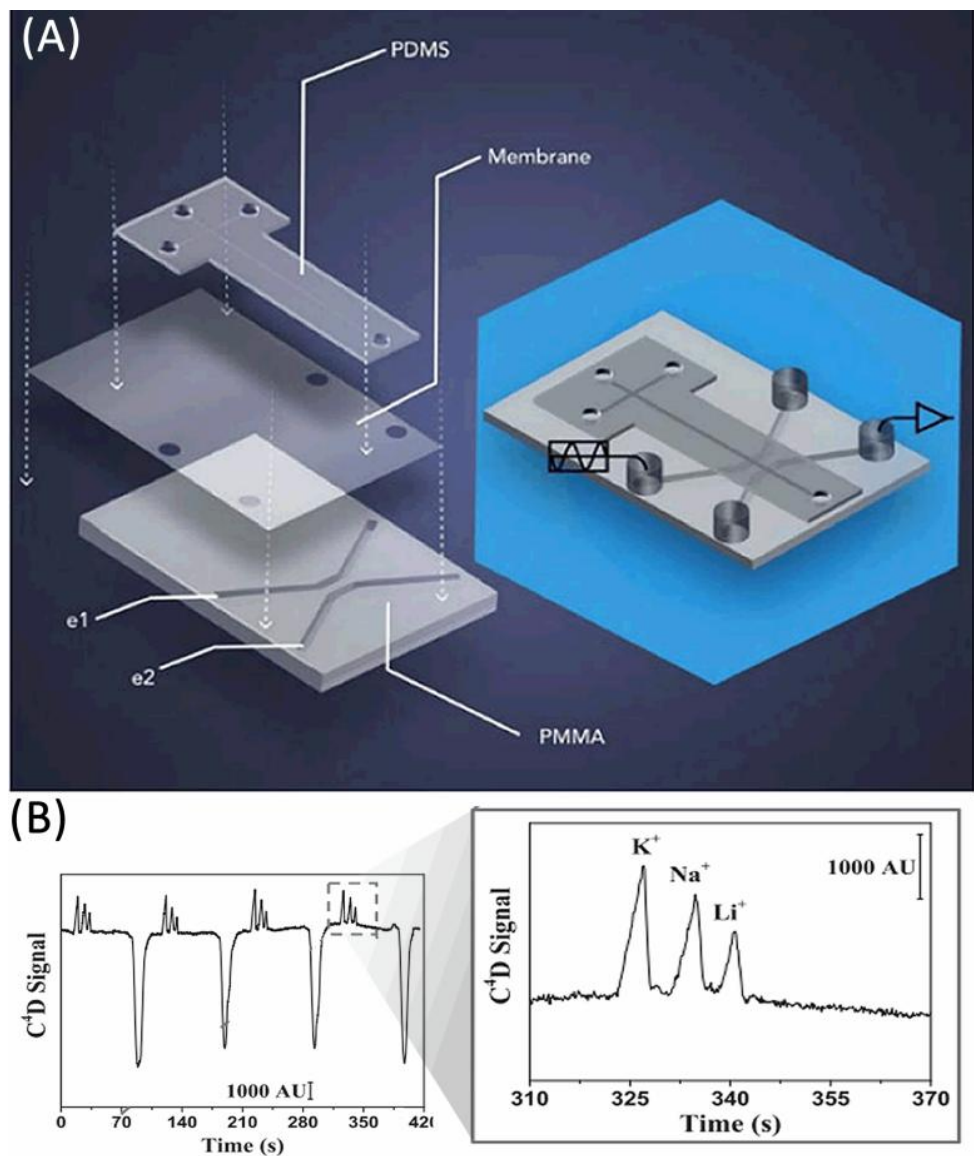

Figure 19. Integrated MCE- $C^{4} D(A)$ Setting-up of the device with ionic solutions as sensing electrodes. e1 and e 2 consist of the excitation and receiver electrodes, respectively. (B) Electrophoretograms of the injection of $\mathrm{K}^{+}, \mathrm{Na}^{+}$, and $\mathrm{Li}^{+}(300 \mu \mathrm{M}$ each) in water using $2 \mathrm{M} \mathrm{KCl}$ as sensing electrodes [107]. Reprint by permission from John Wiley and sons.

\section{Applications}

MCE-EC devices have found widespread use in biological, environmental, and food applications. In this section, some significant examples of studies that engage these systems as fundamental tools to analyse real samples are presented (Tables 1-3). Beyond that, we highlight the analytical improvements attained in each methodology.

\subsection{Application in analysis of biological samples}

MCE-EC devices have been employed for several biological applications, such as for the quantitation of amino acids, proteins, peptides, DNA and inorganic compounds (Table 1). Biological applications focusing on cell analysis were recently reviewed by Lunte's group [108]. In particular, there are several articles by Martin et al. [109] describing PC-12 cells analysis using MCE-EC [73,109-111]. The authors developed a PDMS microchip with integrated microelectrodes, peristaltic pumps; and injection valves. The combination of several analytical steps, such as injection, separation and detection simplify the analysis process and the monitoring of the release of neurotransmitters from a PC-12 cell layers 
immobilized in a collagen coated micropallet. Recently, the authors described a 3D scaffold of polystyrene fibers to immobilize PC-12 cell culture, with integrated automated pumps and a 4-port injection system in a PDMS/polystyrene MCE. The polystyrene substrate was embedded with a Pd decoupler and a CF-WE for off-channel amperometric detection. The authors demonstrated the close-to-real-time analysis of multiple molecules released from the 3D cell culture integrated within the PDMS device[111].

Scott et. al. [112] reported on a microdialysis (MD) sampling coupled directly on a glass-based MCE with amperometric detection. The electrodes were photolithographically patterned in an in-channel configuration, the glass was etched, and then the Pt metal was deposited by sputtering. In this work, the group developed an on-animal separation-based sensor to simultaneously monitor drug metabolism and its behaviour in a freely roaming animal. The device was used to monitor the production of nitrite following introduction of nitroglycerin into the sheep subdermal tissue. The group compared the results obtained by the proposed device with off-line analysis by liquid chromatography (LC)-EC system. Using the proposed system, samples from the first probe (implanted subcutaneously into the epidermal tissue) were analyzed immediately online by MD-ME-EC, every $60 \mathrm{~s}$, with instantly interpretable data, while those from the parallel probe were collected off-line every $10 \mathrm{~min}$ in a centrifuge tube, stored in a $-80{ }^{\circ} \mathrm{C}$ freezer for later analysis by LC-EC system.

Tsai et al.[113] developed a PMMA/photoresist/PMMA microchip with amperometric detection for screening target biological compounds. The fabrication process does not require a replicate mold, and the photoresist is used as both side walls of the microfluidic channels and an adhesive layer for sealing with a PMMA to cover. The photoresist layer is simple and a low-cost alternative to other bonding protocols, which are more demanding, requiring much higher temperature and pressure or the employment of surface plasma treatment for adhesion of polymeric layers constituting the device. The graphite electrodes were manufactured by screen-printed techniques onto PMMA substrate in an off-channel configuration. The proposed device was employed to separate uric and ascorbic acids in human urine with high analytical frequency $\left(72\right.$ injection $\left.\mathrm{h}^{-1}\right)$. Furthermore, the novel device attained results similar to the reported ones using a PDMS/glass microchip [114] in terms of separation efficiency. The rapid identification of target compounds in urine successfully demonstrated the PMMAbased MCE-EC device is a suitable high-throughput screening system for clinical samples. Later, Fernández-la-Villa et al.[115] targeted uric acid in urine samples in patients with gout, using a commercially available portable SU-8/Pyrex microfluidic system. This chip were used 
for more than 60 analysis and cost around $60-70 €$, thus the cost per analysis can become lower than $1 €$.

Meneses et al.[116] evaluated the performance of an in-channel amperometric detection strategy combined with a dual channel PDMS/glass MCE system for the quantification of organic anions. To produce the Pt electrodes, the glass substrate was patterned and developed using a photolithographic method, subsequently the metal was deposited by sputtering. The authors explored the performance of both two- and threeelectrode configurations using two different reference electrodes. Moreover, they evaluated the effect of electrode placement. Baseline noise obtained in this dual-channel configuration (4 pA) was significantly lower than that observed in a single channel configuration (25 pA) integrating an in-channel amperometric detection. The dual-channel device was applied for nitrite detection in a sheep microdialysis sample, reaching nitrite concentration levels of 68 $\mu \mathrm{M}$ in 90 min of continuous perfusion of nitroglycerin.

Schuchert-Shi et al.[117] employed the MCE-C ${ }^{4} \mathrm{D}$ platform to study kidney dysfunctions.. The authors used a PMMA device with two tubular electrodes for an indirect detection of urea in human serum blood by determining the ammonium ion. The results achieved were compared with conventional $\mathrm{CE}$ and with the reference method (standard NADH-based photometric method), showing a good correlation with the reference values than the ones provided by conventional CE. Moreover, Yang et al. [58] reported a threadbased MCE system with 3D gold amperometric electrodes for the detection of urea in whole blood. The gold electrodes were integrated on PMMA substrate with hot embossing and sputtering procedure. Prior to the hot embossing process, a piece of thin aluminium foil was placed between the master mold and the substrate as a sandwich structure that acted as a mask for metal sputtering. The authors showed that 3D-concaved structured electrodes in an offchannel configuration enhanced current response and signal-to-noise ratio of the MCE-EC system of a factor nine and five, respectively, when compared to the responses of a sensing chip integrating conventional 2D sensing electrodes.

Zhang et al. [118] reported a microchip EC enzyme immunoassays platform with amperometry detection to study liver cancer. The Pt electrode was integrated in PDMS/ glass hybrid device through depositing a layer of Pt on the glass substrate employing vacuum sputtering. The authors reported a sensitive detection of $\alpha$-fetoprotein and carcinoembryonic antigen in patients with liver and colon cancers and healthy subjects. The sensitivity of the methodology is comparable with fluorescence detection; the conventional 3,3 ,5,5 - 
tetramethylbenzidine spectrophotometric ELISA assay, attending LOD 20 times lower than the classical method with shorter analysis and simple operation.

Regarding the conductivity detection, Song et al. [119] manufactured a device dedicated to investigate arthritis through detection of lactate in synovial fluid samples from 10 volunteers. The microchip is composed by a PMMA part which contains the separation channel placed in a lab-made contactless electrode plate, which is basically composed by a high-voltage power supply, a CCD detector, and the electrodes. The proposed method was compared with a HPLC reference method showing similar results with some advantages over the reference method, including short analysis time $(<40 \mathrm{~s})$, miniaturization and direct detection without time-consuming sample derivation. Also, Chong et al. [120] described an MCE-C ${ }^{4} \mathrm{D}$ system implemented with an online multi-stacking preconcentration technique based on field enhanced sample injection and micelle-to-solvent stacking. The authors used a glass chip with an MCE chip holder platform with embedded electrodes. The goal was to enhance the sensitivity of the detection of vancomycin in human plasma. The optimized multi-stacking strategy allowed reaching a sensitivity enhancement factor up to 217 . In another study, Chen et al.[121] utilized an on-chip sandwich immunoassay with EC detection to determine the fraction of hemoglobin-A1c in total haemoglobin of human blood. To complement the device, the authors developed a magnetic nanocomposite Au/chitosan/ $\mathrm{Fe}_{3} \mathrm{O}_{4}$, which has a good immobilization ability for anti-human hemoglobin-A1c antibody (HbaA1c $\mathrm{mAb}$ ). The glass device was produced by standard photolithographic and wet chemical etching technique, the gold electrodes were fabricated by electroless plating deposition method. The $\mathrm{HbaA} 1 \mathrm{c} \mathrm{mAb} / \mathrm{Au} / \mathrm{chitosan} / \mathrm{Fe}_{3} \mathrm{O}_{4}$ magnetic nanoparticles were then introduced into the microfluidic device and then immobilized in the device channel by magnetic field. Although the essay platform provided the good analytical results, several assay parameters (for instance magnetic field, particle incubation time, and particle synthesis) must be carefully optimised and controlled. In the framework of the study of lithium in the treatment of bipolar disorders, this compound has to be screened in blood [122], and urine [123] samples using MCE-EC devices. Staal[122] et al. reported a POC device for whole blood analysis, consisting in a polymeric cartridge with a glass microchip and Pt electrodes integrated by sputtering. The authors described significant improvements achieved with this device when compared with the first version previously reported including the use of multiple injections of one sample on a single chip and integrates data analysis.

More recently, Duarte et al.[124] reported a SU-8/Pyrex system with integrated Pt electrodes in an end-channel configuration, for the separation, decomposition (under metal 
catalysis) and detection of low molecular weight S-nitrosothiols (RSNO) in a single run (Figure 20.1). For the first time, the S-nitrosoglutathione (GSNO) and S-nitrosocysteine (CySNO) were separated and quantified via efficient detection of successive nitrite zones produced from RSNO after their decomposition by $\mathrm{Hg}^{2+}$ to nitrite for quantification (Figure 20.2).

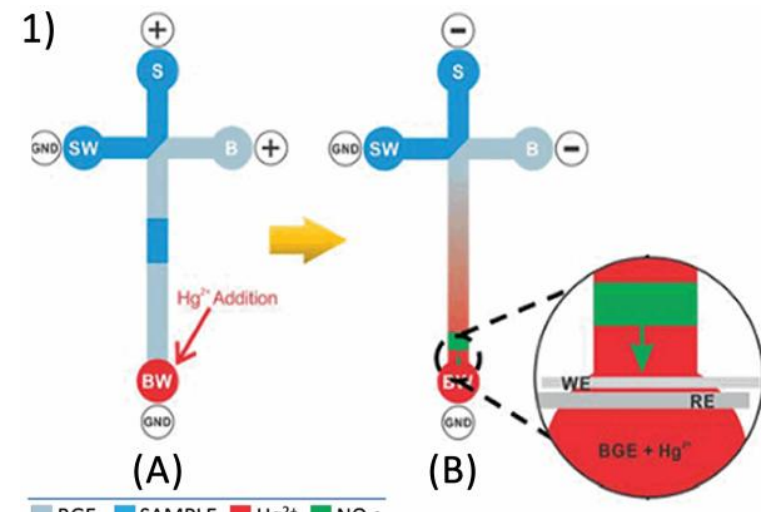

BGE $\square$ SAMPLE $\square \mathrm{Hg}^{2+} \square \mathrm{NO}_{2}{ }^{\circ}$

2)

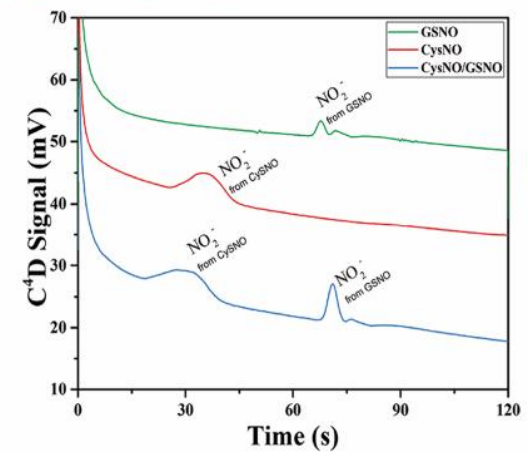

Figure 20. (1) Separation and quantitation of RSNOs in a MCE-EC: 1A Electrophoretic migration of the RSNOs towards the separation channel. Addition of $\mathrm{Hg}^{2+}$ to the BW reservoir $15 \mathrm{~s}$ before the end of this step. 1B Inversion of the separation potential, which leads to the migration of $\mathrm{Hg}^{2+}$ into the separation channel faster than RSNOs, allowing for RSNO decomposition, and migration of the nascent nitrite (in green) towards the electrodes. (2) Electropherograms of CySNO (1 $\mathrm{mM})$, GSNO $(1 \mathrm{mM})$ and the GSNO mixture $(1 \mathrm{mM}) /$ CySNO $(1 \mathrm{mM})$ in blue, red, and black, respectively[124]. Reprint by permission from Royal Society of Chemistry. 
Table 1. Relevant applications of MCE-EC for biological applications.

\begin{tabular}{|c|c|c|c|c|c|c|c|c|c|c|c|c|}
\hline $\begin{array}{l}\text { Detected } \\
\text { Analytes }\end{array}$ & BGE & $\begin{array}{l}\text { Separation } \\
\text { Voltage }\end{array}$ & $\begin{array}{l}\text { Electrode } \\
\text { material }\end{array}$ & $\begin{array}{c}\text { Size } \\
(\mu \mathrm{m})^{\mathrm{c}}\end{array}$ & Format & Detection & Detection potential & $\begin{array}{l}\text { Detection } \\
\text { mode }\end{array}$ & $\begin{array}{c}\text { System } \\
\text { (electrodes) }\end{array}$ & $\begin{array}{c}\text { Concentration } \\
\text { range }(\mu \mathrm{M})\end{array}$ & $\begin{array}{l}\text { LOD } \\
(\mu \mathrm{M})\end{array}$ & Ref. \\
\hline Dopamine & $\begin{array}{l}\text { boric acid } \\
\text { /SDS }\end{array}$ & $280 \mathrm{Vcm}^{-1}$ & Carbon ink & 13 & Microband & Amperometry & $+0.9 \mathrm{~V}$ vs. $\mathrm{Pt}$ & Off-channel & $2-$ & 100 to 300 & 9 & [73] \\
\hline Dopamine & \multirow[b]{2}{*}{$\begin{array}{l}\text { boric acid } \\
\text { /SDS }\end{array}$} & \multirow[b]{2}{*}{$700 \mathrm{~V}$} & \multirow[b]{2}{*}{ Carbon ink } & \multirow[b]{2}{*}{10} & \multirow[b]{2}{*}{ Microband } & \multirow[b]{2}{*}{ Amperometry } & \multirow[b]{2}{*}{$+0.9 \mathrm{~V}$ vs. $\mathrm{Pt}$} & \multirow[b]{2}{*}{ off-channel } & \multirow[b]{2}{*}{$2-$} & NA & 9.3 & \multirow[b]{2}{*}{109} \\
\hline Norepinephrine & & & & & & & & & & NA & 7.5 & \\
\hline Dopamine & \multirow{2}{*}{ TES/SDS } & \multirow{2}{*}{$160 \mathrm{Vcm}^{-1}$} & \multirow{2}{*}{$\begin{array}{l}\text { Carbon } \\
\text { fiber }\end{array}$} & \multirow{2}{*}{33} & \multirow{2}{*}{ Microdisk } & \multirow{2}{*}{ Amperometry } & \multirow{2}{*}{$+0.9 \mathrm{~V}$ vs. $\mathrm{Pt}$} & \multirow{2}{*}{ off-channel } & \multirow{2}{*}{$2-$} & \multirow{2}{*}{ NA } & NA & \multirow{2}{*}{ [110] } \\
\hline Norepinephrine & & & & & & & & & & & 4 & \\
\hline Dopamine & \multirow{2}{*}{ TES/SDS } & \multirow{2}{*}{$330 \mathrm{Vcm}^{-1}$} & \multirow{2}{*}{$\begin{array}{l}\text { Carbon } \\
\text { fiber }\end{array}$} & \multirow{2}{*}{33} & & & & & & & 0.6 & \\
\hline Norepinephrine & & & & & (7) & 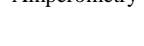 & (1) & - & 2 & (2) & NA & 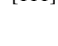 \\
\hline Nitrite & PBS & $-1600 \mathrm{~V}$ & $\mathrm{Pt}$ & 15 & Microband & Amperometry & $+1.05 \mathrm{~V}$ vs. $\mathrm{Pt}$ & In-channel & $2-$ & 2.5 to 25 & 0.75 & [112] \\
\hline Uric acid & PBS & $100 \mathrm{Vcm}^{-1}$ & graphite & 50 & Microband & Amperometry & $10.7 \mathrm{~V}$ vs. $\mathrm{Ag} / \mathrm{AgCl}$ & off-channel & 3- & 10 to 1000 & NA & [113] \\
\hline L-ascorbic acid & & & & & & & & & & & & \\
\hline Nitrite & & & & & & & $\begin{array}{l}+1.1 \mathrm{~V} \text { vs. } \\
\mathrm{Ag} / \mathrm{AgCl}^{\mathrm{a}}\end{array}$ & & & 3.1 to 50 & 1.44 & \\
\hline Nitrite & & & & & & & $+1.1 \mathrm{~V}$ vs. $\mathrm{Pt}^{\mathrm{b}}$ & & & 3.1 to 50 & 0.58 & \\
\hline $\mathrm{H}_{2} \mathrm{O}_{2}$ & boric acid/ & $-2.4 \mathrm{kV}$ & Pt & 15 & Microband & Amperometry & $\begin{array}{l}+1.1 \mathrm{~V} v \mathrm{vs} \\
\mathrm{Ag} / \mathrm{AgCl}^{\mathrm{a}}\end{array}$ & In-channel & 3 & NA & 7.37 & [116] \\
\hline $\mathrm{H}_{2} \mathrm{O}_{2}$ & & & & & & & $+1.1 \mathrm{~V}$ vs. $\mathrm{Pt}^{\mathrm{b}}$ & & & NA & 0.75 & \\
\hline Tyrosine & & & & & & & $\begin{array}{l}+1.1 \mathrm{~V} \mathrm{vs.} \\
\mathrm{Ag} / \mathrm{AgCl}^{\mathrm{a}}\end{array}$ & & & NA & NA & \\
\hline Tyrosine & & & & & & & $+1.1 \mathrm{~V}$ vs. $\mathrm{Pt}^{\mathrm{b}}$ & & & NA & 0.14 & \\
\hline Urea & & & & & & & & & & 100 to 10000 & 100 & \\
\hline $\mathrm{K}^{+}$ & & & & & & & & & & & & \\
\hline $\mathrm{Na}^{+}$ & MES & $300 \mathrm{Vcm}^{-1}$ & $\mathrm{Cr} / \mathrm{Au}$ & 300 & Microband & Amperometry & -0.23 V vs. Pt & Off-channel & $3-$ & & & [58] \\
\hline $\mathrm{Ca}^{2+}$ & & & & & & & & & & NA & NA & \\
\hline $\mathrm{Mg}^{2+}$ & & & & & & & & & & & & \\
\hline $\mathrm{NH}_{4}^{+}$ & & & & & & & & & & & & \\
\hline $\begin{array}{l}\text { S-nitroso } \\
\text { glutathione }\end{array}$ & Arginine/ & $1000 \mathrm{Vcm}^{-1}$ & $\mathrm{Pt}$ & 50 & Microband & Amperometry & $0.7 \mathrm{~V}$ vs. $\mathrm{Pt}$ & End-channel & $2-$ & 130 to 675 & 20 & [124] \\
\hline S-nitrosocysteine & acetic acid & & & & & Conductivity & & & & & & \\
\hline Nitrite & & & $\mathrm{Pd}$ & 40 & Microband & Amperometry & $0.85 \mathrm{~V}$ vs. $\mathrm{Ag} / \mathrm{AgCl}$ & End-channel & 3- & & 20 & \\
\hline $\begin{array}{l}\text { Nitrate } \\
\text { Nitrite }\end{array}$ & $\begin{array}{l}\text { boric acid/ } \\
\text { TTAB }\end{array}$ & $1.2 \mathrm{kV}$ & $\mathrm{Cu}$ & 1000 & band & Conductivity & & & & NA & $\begin{array}{c}67 \\
308 \\
\end{array}$ & [125] \\
\hline $\begin{array}{c}\text { Carcinoembryonic } \\
\text { antigen }\end{array}$ & Britton- & & Pt & 200 & "U"-shaned & & $05 \mathrm{~V} \cup \mathrm{A \sigma} / \mathrm{A} \sigma \mathrm{Cl}$ & & 3 & $\begin{array}{c}2.76 \times 10^{-6} \text { to } \\
3.66 \times 10^{-4}\end{array}$ & $\begin{array}{r}1.38 \\
\times 10^{-6} \\
\end{array}$ & \\
\hline$\alpha$-fetoprotein & $\begin{array}{c}\text { Robinson/ } \\
\mathrm{H}_{2} \mathrm{O}_{2}\end{array}$ & $1.4 \mathrm{kV}$ & $\mathrm{Pt}$ & 200 & "U"-shaped & amperometry & $0.5 \mathrm{~V}$ vs. $\mathrm{Ag} / \mathrm{AgCl}$ & End-channel & 3- & $\begin{array}{c}7.14 \times 10^{-6} \text { to } \\
1.14 \times 10^{-3}\end{array}$ & $\begin{array}{r}1.85 \\
\times 10^{-4} \\
\end{array}$ & [118] \\
\hline Lactate & $\begin{array}{c}\text { TRIS/HCl/ } \\
\text { CTAB }\end{array}$ & $2 \mathrm{kV}$ & $\mathrm{Pt}$ & - & microband & conductivity & - & $\mathrm{CCD}$ & Parallel & 540 to 5370 & 6.5 & [119] \\
\hline Uric acid & $\begin{array}{l}\mathrm{MES} / \\
\mathrm{NaOH} / \\
\mathrm{SDS}\end{array}$ & $1 \mathrm{kV}$ & $\mathrm{Ti} / \mathrm{Pt}$ & 50 & microband & conductivity & $0.8 \mathrm{~V}$ vs. $\mathrm{Pt}$ & End-channel & $3-$ & 20 to 400 & 10 & [115] \\
\hline $\mathrm{Li}^{+}$ & $\begin{array}{c}\text { Lysine/ } \\
\text { histidine/. } \\
\text { Tartaric } \\
\text { acid } \\
\text { hydroxypro } \\
\text { pylmethylc } \\
\text { ellulose }\end{array}$ & - & $\mathrm{Pt}$ & 56 & microband & conductivity & - & $C^{4} \mathrm{D}$ & Antiparallel & - & - & [122] \\
\hline $\mathrm{Li}^{+}$ & $\begin{array}{c}\text { Arginine/ } \\
\text { maleic acid/ } \\
\text { 18-crown-6 }\end{array}$ & $4 \mathrm{kV}$ & Copper & 35 & microband & conductivity & - & $C^{4} D$ & Antiparallel & - & 7.5 & [123] \\
\hline Vancomycin & $\begin{array}{l}\text { Acetic acid/ } \\
\text { SDS }\end{array}$ & $1.5 \mathrm{kV}$ & - & 200 & microband & conductivity & - & $C^{4} \mathrm{D}$ & Antiparallel & 5.2 to 44.8 & 0.9 & [120] \\
\hline Urea & $\begin{array}{c}\text { Arginine/ } \\
\text { maleic acid/ } \\
\text { 18-crown-6 }\end{array}$ & $5 \mathrm{kV}$ & - & 4000 & band & conductivity & - & $C^{4} \mathrm{D}$ & Antiparallel & 2000 to 30000 & 600 & [117] \\
\hline
\end{tabular}




\begin{tabular}{|c|c|c|c|c|c|c|c|c|c|c|c|c|}
\hline Hemoglobin A1c & Phosphate & $0.6 \mathrm{kV}$ & gold & 40 & microband & amperometry & 0.5 vs. $\mathrm{Ag} / \mathrm{AgCl}$ & End-channel & 3- & $\begin{array}{c}7.35 \times 10^{-4} \text { to } \\
220\end{array}$ & $\begin{array}{r}3.67 \\
\times 10^{-4} \\
\end{array}$ & [121] \\
\hline & \multicolumn{12}{|c|}{$\mathrm{NA}=$ not available } \\
\hline & \multirow{2}{*}{\multicolumn{12}{|c|}{$\begin{array}{l}\text { * tetradecyltrimethylammonium bromide (TTAB), 2-morpholinoethanesulfonic acid monohydrate (MES), sodium dodecyl sulfate (SDS), tris- hydroxymethyl]- } \\
\text { aminomethane (TRIS), Cetrimonium bromide (CTAB). }\end{array}$}} \\
\hline & & & & & & & & & & & & \\
\hline & \multicolumn{12}{|c|}{${ }^{* a}$ one single WE electrode } \\
\hline & \multicolumn{12}{|c|}{${ }^{* b}$ two WE electrodes (dual) } \\
\hline & \multicolumn{12}{|c|}{${ }^{{ }^{\mathrm{c}} \mathrm{c}}$ diameter for microdisk or width for microband } \\
\hline
\end{tabular}

\subsection{Applications in analysis of food}

Table 2 summarizes the most significant examples of MCE-EC devices for food analysis. In particular, MCE with conductivity detection was developed for the quantitative analysis of inorganic and organic ions in beverages, either alcoholic or non-alcoholic. Lee $e t$. al. [126] reported the production of semi-circular detection electrodes in a glass substrate using integration strategies such as sputtering for the deposition of metal electrodes and liftoff as a standard process. The semi-circular Au electrodes in the head-to-head geometry were assembled by the two plates bonding, with metal deposited on the cover plate and within the channel of the base plate. The authors compared the results achieved after the injection of inorganic cations, using semi-circular electrodes and planar electrodes, giving rise to a lower standard deviation (7.8\%) for the semi-circular geometry compared to $18.3 \%$ for the planar one. The proposed device was applied for the screening of inorganic compounds in red wine, commercial sports drinks, and drinking waters.

Recently, Quero et al.[99] proposed a polyester thread-based assembled in a 3Dprinted platform as a novel MCE device with $\mathrm{C}^{4} \mathrm{D}$ detection (Figure 21.1). This 3D printed platform was designed with four reservoirs and circular patterns to embrace the copper electrodes. The device was employed to screen $\mathrm{Na}^{+}$and $\mathrm{K}^{+}$ions in diet soft drink and regular soft drink (Figure 21.2), achieving remarkable LODs $\left(0.50\right.$ and $0.69 \mu \mathrm{M}$ for $\mathrm{K}^{+}$and $\mathrm{Na}^{+}$, respectively), which were similar or lower than those described for $\mathrm{C}^{4} \mathrm{D}$ in silica capillary and other microchip devices[127]. This improvement in the detectability is owing to the thin isolation layer $(7.5 \mu \mathrm{m})$ of the polymer that covered the commercial copper wire used as electrode, clearly indicating that the smaller the thickness of the isolation layer, the lower the electrical impedance of the capacitors formed between the electrodes and the channel solution. 




Figure 21. Polyester thread-based MCE-EC (1) The3D-printed platform device assembled in an aluminium cage. Top insert : injection intersection, down insert : $\mathrm{C}^{4} \mathrm{D}$ electrodes. (2) Electropherograms of (A) a standard solution of $\mathrm{K}^{+}$and $\mathrm{Na}^{+}(75 \mu \mathrm{M}$, each); (B) lemon and (C) cola diet soft drinks [99]. Reprint by permission from Elsevier.

Amperometric detection in MCE systems is also widely used to quantitate organic compounds in beverages and oils. Du and Fung [128] developed a PMMA-based microchip with dual opposite electrodes in an end-channel configuration. The $\mathrm{CF}$ electrodes were integrated with epoxy using embedded strategy. The authors achieved analytical features, such as LODs $(0.031-0.21 \mathrm{mg} / \mathrm{L})$, repeatability $(2.0-3.3 \% \mathrm{RSD}, \mathrm{n}=5)$, working range and recovery rate (94-108\%), suitable for peak purity assessment of polyphenols in red wine samples. Petroni et. al. [74] reported a hybrid microchip (PDMS/ acrylic) with integrated handmade graphite electrodes (3-electrode cell format in an end-channel configuration) using a screen-printed approach to separate target compounds in drinking water. The new methodology permits to discriminate nitrite from other anions naturally occurring in the sample $\left(\mathrm{F}^{-}, \mathrm{Cl}^{-}, \mathrm{NO}_{3}^{-}\right.$and $\left.\mathrm{SO}_{4}^{-2}\right)$, thus avoiding any interference. Furthermore, the group compared the results from the proposed method with the ones of a reference method and performed recovery studies (95.4\%) in order to validate the methodology. Aghdam et al. [45] reported a hybrid microchip (SU-8/ glass) to separate and detect synthetic antioxidants in edible oils by commercial integrated Au electrodes (3-electrode cell format in an end-channel configuration). The proposed method was validated by a reference HPLC method. The authors applied the paired $t$-test revealing that there is no difference between obtained results with a confidence level of $95 \%$. 
Table 2. Relevant applications of MCE-EC for food applications

\begin{tabular}{|c|c|c|c|c|c|c|c|c|c|c|c|c|}
\hline Detected Analytes & BGE & $\begin{array}{l}\text { Separation } \\
\text { voltage }\end{array}$ & $\begin{array}{l}\text { Electrode } \\
\text { material }\end{array}$ & $\begin{array}{l}\text { Size }^{\mathrm{a}} \\
(\mu \mathrm{m})\end{array}$ & Format & Detection & $\begin{array}{c}\text { Detection } \\
\text { potential } \\
\text { (amperometry) }\end{array}$ & $\begin{array}{l}\text { Detection } \\
\text { alignment }\end{array}$ & $\begin{array}{c}\text { System } \\
\text { (electrodes) }\end{array}$ & $\begin{array}{l}\text { Concentration } \\
\text { range }\end{array}$ & LOD & Ref. \\
\hline $\mathrm{K}^{+}$ & \multirow{3}{*}{ MES/HIS } & \multirow{3}{*}{$1 \mathrm{kV}$} & \multirow{3}{*}{ copper } & \multirow{3}{*}{1000} & \multirow{3}{*}{ band } & \multirow{3}{*}{ Conductivity } & & \multirow{3}{*}{$C^{4} D$} & \multirow{3}{*}{ Antiparallel } & $1.67-125^{1}$ & $0.5^{1}$ & \multirow{3}{*}{ [99] } \\
\hline $\mathrm{Na}^{+}$ & & & & & & & & & & $2.30-125^{1}$ & $0.69^{1}$ & \\
\hline $\mathrm{Li}^{+}$ & & & & & & & & & & $3.57-125^{1}$ & $1.07^{1}$ & \\
\hline $\mathrm{K}^{+}$ & \multirow{3}{*}{ MES/HIS } & \multirow{3}{*}{$300 \mathrm{Vcm}^{-1}$} & \multirow{3}{*}{$\mathrm{Au}$} & \multirow{3}{*}{ NA } & \multirow{3}{*}{$\begin{array}{l}\text { Semi } \\
\text { circular }\end{array}$} & \multirow{3}{*}{ Conductivity } & & \multirow{3}{*}{$C^{4} D$} & \multirow{3}{*}{$\begin{array}{l}\text { Head-to- } \\
\text { head }\end{array}$} & \multirow{3}{*}{ NA } & \multirow{3}{*}{ NA } & \multirow{3}{*}{ [126] } \\
\hline $\mathrm{Mg}^{2+}$ & & & & & & & & & & & & \\
\hline $\begin{array}{l}\mathrm{Ca}^{2+} \\
\mathrm{Na}^{+}\end{array}$ & & & & & & & & & & & & \\
\hline $\begin{array}{c}\text { Trans- } \\
\text { Resveratrol } \\
\end{array}$ & \multirow{5}{*}{$\begin{array}{l}\text { Borate/ } \\
\beta-\mathrm{CD} / \\
\mathrm{MeOH}\end{array}$} & \multirow{5}{*}{$12 \mathrm{kV}$} & \multirow{5}{*}{ carbon- fiber } & \multirow{5}{*}{30} & \multirow{5}{*}{$\begin{array}{l}\text { Micro } \\
\text { disk }\end{array}$} & \multirow{5}{*}{ Amperometry } & \multirow{5}{*}{$\begin{array}{c}1.0 \mathrm{~V} / 0.8 \mathrm{~V} \text { vs. } \\
\mathrm{Ag} / \mathrm{AgCl}\end{array}$} & \multirow{5}{*}{ End-channel } & \multirow{5}{*}{$\begin{array}{c}2- \\
\text { electrodes }\end{array}$} & $0.28-20^{2}$ & $0.031^{2}$ & \multirow{5}{*}{ [128] } \\
\hline$(+)$ - Catechin & & & & & & & & & & $0.28-40^{2}$ & $0.11^{2}$ & \\
\hline (-)- Epicatechin & & & & & & & & & & $0.28-40^{2}$ & $0.036^{2}$ & \\
\hline Quercetin & & & & & & & & & & $0.83-40^{2}$ & $0.16^{2}$ & \\
\hline Gallic acid & & & & & & & & & & $1.0-80^{2}$ & $0.21^{2}$ & \\
\hline Nitrite & \multirow{2}{*}{$\begin{array}{c}\text { Phosphate/ } \\
\text { CTAB }\end{array}$} & \multirow{2}{*}{ NA } & \multirow{2}{*}{ graphite } & \multirow{2}{*}{400} & Micro & A mprometri & & Fnd channel & $3-$ & $0.5-5^{2}$ & $8.2^{1}$ & [744] \\
\hline Ascorbic acid & & & & & band & Amperometry & & End-cnamnel & electrodes & $20-200^{1}$ & $12.7^{1}$ & {$[1 / 4]$} \\
\hline TBHQ & & & & & & & & & & $10-100^{1}$ & $0.8^{1}$ & \\
\hline BHA & Borate & $1 \mathrm{kV}$ & $\mathrm{Ti} / \mathrm{Au}$ & 50 & $\begin{array}{l}\text { Vilcro } \\
\text { band }\end{array}$ & Amperometry & $+1.0 \mathrm{~V}$ vs. $\mathrm{Au}$ & End-channel & $\begin{array}{c}3- \\
\text { electrodes }\end{array}$ & $10-100^{1}$ & $1.4^{1}$ & [45] \\
\hline PG & & & & & & & & & & $20-200^{1}$ & $4.3^{1}$ & \\
\hline
\end{tabular}

$\mathrm{NA}=$ not available

*2-morpholinoethanesulfonic acid monohydrate (MES), histidine (HIS), propyl gallate (PG), tert-butyl hydro- quinone (TBHQ), and butylated hydroxyanisole (BHA).

${ }^{* 1} \mu \mathrm{M} * 2 \mathrm{mg} / \mathrm{L}$

${ }^{*}$ a Diameter for microdisk or width for microband

\subsection{Application in analyses of environmental samples}

The applicability of MCE-C $\mathrm{C}^{4} \mathrm{D}$ systems for screening degradation products in environmental samples is widely explored by Wang group [129]. The authors measured chemical warfare agent degradation products in natural (river) water using a PMMA-based MCE-EC. The Al electrodes (in anti-parallel configuration) were fixed in PMMA substrate using a common epoxy glue. Later, the authors detected low-energy ionic explosives and nerve agent degradation products using the same microchip with a movable detection cell [130]. Ding et. al. [131] have also demonstrated the separation of organophosphonate nerve agent degradation products using a PDMS device with embedded electrodes in an anti-parallel configuration. Under optimal conditions, the analysis of five compounds was achieved in less than 2 min. This new methodology can be applied for on-site monitoring of degradation products of chemical warfare agents in water samples.

The feasibility of amperometric detection in environmental samples was also described by Pelle et. al.[132] using a glass/PMMA microchip. The carbon black nanoparticle (CB-NPs) electrodes were transferred into the PMMA substrate by pressure (Figure 22.A). For the first time, the authors describe a MCE-EC workflow including an external sample treatment step for monitoring phenyl carbamate in real environmental samples (river, lake, and irrigation waters). The authors achieved analytical features, such as LODs $(7-12 \mu \mathrm{M})$, 
relative standard deviation ( $\mathrm{RSD}, \mathrm{n}=10$ ) for the peak intensity and migration times below $3 \%$ and $8 \%$, respectively, and working range $(25-125 \mu \mathrm{M})$. These features showed the suitability of the press-transferred carbon black nanoparticles detectors for the screening of pesticides (Figure 22.B). Significant other applications are summarized in Table 3.

(A)



(B)

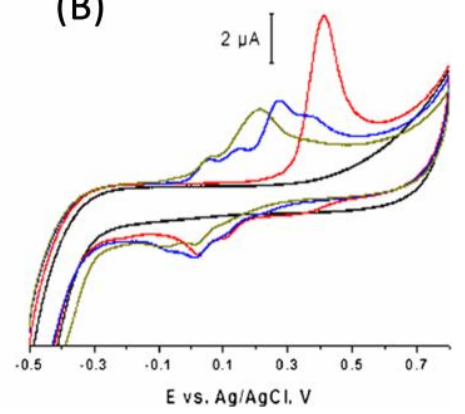

Figure 22. (A) Scheme of the carbon black nanoparticulate (CB-NPs)-based electrode onto a PMMA device, with a zoom on the CB-NPs electroactive film. (B) Cyclic voltammograms of isoprocarb (red line), carbofuran (blue line) and carbaryl (green line) hydrolytic forms at $0.1 \mathrm{mM}[132]$. Reprint by permission from Springer Nature.

Table 3. Relevant applications of MCE-EC for environmental applications.

\begin{tabular}{|c|c|c|c|c|c|c|c|c|c|c|c|}
\hline $\begin{array}{l}\text { Detected } \\
\text { Analytes }\end{array}$ & BGE & $\begin{array}{l}\text { Separation } \\
\text { voltage }\end{array}$ & $\begin{array}{l}\text { Electrode } \\
\text { material }\end{array}$ & $\begin{array}{l}\text { Size }^{\mathrm{c}} \\
(\mu \mathrm{m})\end{array}$ & Format & Detection & $\begin{array}{l}\text { Detection } \\
\text { mode }\end{array}$ & System & $\begin{array}{c}\text { Concentration } \\
\text { range }\end{array}$ & LOD & Ref. \\
\hline PMPA & \multirow{4}{*}{ MES/HIS } & \multirow{4}{*}{$-250 \mathrm{~V} \mathrm{~cm}^{-1}$} & \multirow{4}{*}{$\mathrm{Al}$} & \multirow{4}{*}{800} & \multirow{4}{*}{ band } & \multirow{4}{*}{ Conductivity } & \multirow{4}{*}{$C^{4} \mathrm{D}$} & \multirow{4}{*}{ antiparallel } & \multirow{4}{*}{$0.3-100^{2}$} & \multirow{4}{*}{$0.48-0.86^{2}$} & \multirow{4}{*}{ [129] } \\
\hline IMPA & & & & & & & & & & & \\
\hline EMPA & & & & & & & & & & & \\
\hline MPA & & & & & & & & & & & \\
\hline $\mathrm{CH}_{3} \mathrm{NH}_{3}{ }^{+}$ & \multirow{3}{*}{ MES/HIS } & \multirow{3}{*}{$208 \mathrm{~V} \mathrm{~cm}^{-1}$} & \multirow{3}{*}{$\mathrm{Al}$} & \multirow{3}{*}{800} & \multirow{3}{*}{ band } & \multirow{3}{*}{ Conductivity } & \multirow{3}{*}{$C^{4} \mathrm{D}$} & \multirow{3}{*}{ antiparallel } & \multirow{3}{*}{ NA } & \multirow{3}{*}{ NA } & \multirow{3}{*}{ [130] } \\
\hline $\mathrm{NH}_{4}{ }^{+}$ & & & & & & & & & & & \\
\hline $\mathrm{Na}^{+}$ & & & & & & & & & & & \\
\hline IMPA & \multirow{5}{*}{ MES/HIS } & \multirow{5}{*}{$1.2 \mathrm{kV}$} & \multirow{5}{*}{$\mathrm{Al}$} & \multirow{5}{*}{15000} & \multirow{5}{*}{ band } & \multirow{5}{*}{ Conductivity } & \multirow{5}{*}{$C^{4} \mathrm{D}$} & \multirow{5}{*}{ antiparallel } & \multirow{5}{*}{$1.3-4.5^{2}$} & $4.5^{3}$ & \multirow{5}{*}{ [131] } \\
\hline PMPA & & & & & & & & & & $2.0^{3}$ & \\
\hline EDPA & & & & & & & & & & $2.0^{3}$ & \\
\hline EMPA & & & & & & & & & & $2.9^{3}$ & \\
\hline MPA & & & & & & & & & & $1.3^{3}$ & \\
\hline carbofuran & \multirow{3}{*}{ Borate } & \multirow{3}{*}{$1 \mathrm{kV}$} & \multirow{3}{*}{ carbon black } & & & Amperometry & & & & $99^{1}$ & \\
\hline isoprocarb & & & & $0.030^{\mathrm{d}}$ & nanoband & $+0.70 \mathrm{~V}$ vs & channel & electrodes & $25-125^{1}$ & 71 & [132] \\
\hline carbaryl & & & & & & $\mathrm{Ag} / \mathrm{AgCl}$ & & & & $12^{1}$ & \\
\hline
\end{tabular}

*Isopropyl methylphosphonic acid (IMPA), pinacolyl methylphosphonic acid (PMPA), O-ethyl-N,N-dimethyl phosphoramidate (EDPA), ethyl methylphosphonic acid (EMPA), and methylphosphonic acid (MPA), 2-morpholinoethanesulfonic acid monohydrate (MES), histidine (HIS).

$\mathrm{NA}=$ no available

$* 1 \mu \mathrm{M} * 2 \mathrm{mg} / \mathrm{L} * 3 \mathrm{ppm}$

*c width

$*^{\mathrm{d}}$ nanoparticles size

\section{Conclusion}

The alliance between microfluidics, $\mathrm{CE}$ and EC is an attractive approach since it combines synergistically the inherent features of each of these techniques and enhances their potential to 
overpass the encountered challenges within total analysis microsystems. In this review, we addressed the recent advances in MCE-EC configurations, materials and fabrication process, focusing on the electrode's fabrication and their electrochemical performance. The reviewed studies clearly show that MCE-EC devices are being a reality. Although almost no devices are currently being developed in mass production, the ones we have described here are very promising. And it is important now (and urgent) that joint efforts of academic researchers and developers (star ups) are dedicated to the study of industrialization and scaling up. The future of MCE-EC is also expected to expand thanks to further advancements in automation technologies and more importantly the integration of smartphones facilities (Bluetooth, etc.) that would enable their use for in-situ analysis to target compounds in near real-time.

\section{Acknowledgements}

Brazilian Federal Agency for Support and Evaluation of Graduate Education (CAPES), French Committee for the Evaluation of Academic and Scientific Cooperation with Brazil (COFECUB, project Ph C 952/19) and "Centre national de la recherche scientifique" (CNRS, International Emerging Actions (IEA) 2019-2021 "Dispositifs microfluidiques innovants pour la santé et les sciences de la vie) are acknowledged for financial support and scholarship.

\section{Bibliography}

[1] S.C. Terry, J.H. Herman, J.B. Angell, A Gas Chromatographic Air Analyzer Fabricated on a Silicon Wafer, IEEE Transactions on Electron Devices. 26 (1979) 1880-1886. https://doi.org/10.1109/T-ED.1979.19791.

[2] A. Manz, Y. Miyahara, J. Miura, Y. Watanabe, H. Miyagi, K. Sato, Design of an open-tubular column liquid chromatograph using silicon chip technology, Sensors and Actuators B: Chemical. 1 (1990) 249-255. https://doi.org/10.1016/0925-4005(90)80210-Q.

[3] G.M. Whitesides, The origins and the future of microfluidics, Nature. 442 (2006) 368-373. https://doi.org/10.1038/nature05058.

[4] E.P. Randviir, C.E. Banks, Electrode substrate innovation for electrochemical detection in microchip electrophoresis, Electrophoresis. 36 (2015) 1845-1853. https://doi.org/10.1002/elps.201500153.

[5] M. Militropoulou, C. Lecomte, C. Bayle, F. Couderc, N.K. Karamanos, Laser-induced fluorescence as a powerful detection tool for capillary electrophoretic analysis of heparin/heparan sulfate disaccharides, Biomedical Chromatography. 17 (2003) 39-41. https://doi.org/10.1002/bmc.207. 
[6] P. Schulze, D. Belder, Label-free fluorescence detection in capillary and microchip electrophoresis, Analytical and Bioanalytical Chemistry. 393 (2009) 515-525. https://doi.org/10.1007/s00216-008-2452-7.

[7] L. Chen, J. Choo, Recent advances in surface-enhanced Raman scattering detection technology for microfluidic chips, Electrophoresis. 29 (2008) 1815-1828.

https://doi.org/10.1002/elps.200700554.

[8] T.M. Floyd, M.A. Schmidt, K.F. Jensen, Silicon micromixers with infrared detection for studies of liquid-phase reactions, Industrial and Engineering Chemistry Research. 44 (2005) 23512358. https://doi.org/10.1021/ie049348j.

[9] D.J. Harrison, P.G. Glavina, A. Manz, Towards miniaturized electrophoresis and chemical analysis systems on silicon: an alternative to chemical sensors, Sensors and Actuators: B. Chemical. 10 (1993) 107-116. https://doi.org/10.1016/0925-4005(93)80033-8.

[10] A. Manz, J.C. Fettinger, E. Verpoorte, H. Lüdi, H.M. Widmer, D.J. Harrison, Micromachining of monocrystalline silicon and glass for chemical analysis systems: A look into next century's technology or just a fashionable craze?, TrAC - Trends in Analytical Chemistry. 10 (1991) 144149. https://doi.org/10.1016/0165-9936(91)85116-9.

[11] M. Jansson, Emmer, J. Roeraade, Some design considerations in miniaturized electrokinetic separation systems, Journal of High Resolution Chromatography. 12 (1989) 797-801. https://doi.org/10.1002/jhrc.1240121207.

[12] R. Virtanen, Zone electrophoresis in a narrow bore tube employing Potentiometrie detection. Theoretical and experimental study, Acta Polytechnica Scandinavica - Chemical Technology Series. 123 (1974) 1-67.

[13] R.A. Wallingford, A.G. Ewing, Capillary Zone Electrophoresis with Electrochemical Detection In 12.7 $\mu$ M Diameter Columns, Analytical Chemistry. 60 (1988) 1972-1975. https://doi.org/10.1021/ac00169a027.

[14] F.E.P. Mikkers, F.M. Everaerts, P.E.M. Verheggen, High-performance zone electrophoresis, Journal of Chromatography A. 169 (1979) 11-20.

[15] A. Fernández-la-Villa, D.F. Pozo-Ayuso, M. Castaño-Álvarez, Microfluidics and electrochemistry: an emerging tandem for next-generation analytical microsystems, Current Opinion in Electrochemistry. 15 (2019) 175-185. https://doi.org/10.1016/j.coelec.2019.05.014.

[16] D.G. Rackus, M.H. Shamsi, A.R. Wheeler, Electrochemistry, biosensors and microfluidics: a convergence of fields, Chemical Society Reviews. 44 (2015) 5320-5340. https://doi.org/10.1039/c4cs00369a.

[17] J.F. Wong, M.D. Mohan, E.W.K. Young, C.A. Simmons, Integrated electrochemical measurement of endothelial permeability in a 3D hydrogel-based microfluidic vascular model, Biosensors and Bioelectronics. 147 (2020) 956-5663. https://doi.org/10.1016/j.bios.2019.111757.

[18] E. Ollikainen, T. Aitta-aho, M. Koburg, R. Kostiainen, T. Sikanen, Rapid analysis of intraperitoneally administered morphine in mouse plasma and brain by microchip 
electrophoresis-electrochemical detection, Scientific Reports. 9 (2019) 3311. https://doi.org/10.1038/s41598-019-40116-5.

[19] Y.S. Huh, T.J. Park, E.Z. Lee, W.H. Hong, S.Y. Lee, Development of a fully integrated microfluidic system for sensing infectious viral disease, Electrophoresis. 29 (2008) 2960-2969. https://doi.org/10.1002/elps.200700823.

[20] A. Yakoh, S. Chaiyo, W. Siangproh, O. Chailapakul, 3D Capillary-Driven Paper-Based Sequential Microfluidic Device for Electrochemical Sensing Applications, ACS Sensors. 4 (2019) 12111221. https://doi.org/10.1021/acssensors.8b01574.

[21] R.A. Mathies, A.N. Glazer, K. Lao, A.T. Woolley, Electrochemical detector integrated on microfabricated capillary electrophoresis chips, 5,906,723, 1996.

[22] A.T. Woolley, K. Lao, A.N. Glazer, R.A. Mathies, Capillary Electrophoresis Chips with Integrated Electrochemical Detection, Analytical Chemistry. 70 (1998) 684-688.

https://doi.org/10.1080/10826079808001954.

[23] S.J. Baldock, N. Bektas, P.R. Fielden, N.J. Goddard, L.W. Pickering, J.E. Prest, R.D. Snook, B.J.T. Brown, D.I. Vaireanu, Isotachophoresis on Planar Polymeric Substrates, Micro Total Analysis Systems '98. (1998) 359-362. https://doi.org/10.1007/978-94-011-5286-0_85.

[24] P.R. Fielden, S.J. Baldock, N.J. Goddard, L.W. Pickering, J.E. Prest, R.D. Snook, B.J.T. Brown, D.I. Vaireanu, A Miniaturized Planar Isotachophoresis Separation Device for Transition Metals with Integrated Conductivity Detection, Micro Total Analysis Systems '98. (1998) 323-326. https://doi.org/10.1007/978-94-011-5286-0_76.

[25] A.J. Zemann, E. Schnell, D. Volgger, G.K. Bonn, Contactless Conductivity Detection for Capillary Electrophoresis, Analytical Chemistry. 70 (1998) 563-567.

https://doi.org/10.1021/ac9707592.

[26] J. a F. Da Silva, C.L. Do Lago, An oscillometric detector for capillary electrophoresis, Analytical Chemistry. 70 (1998) 4339-4343. https://doi.org/10.1021/ac980185g.

[27] R.M. Guijt, E. Baltussen, G. Der Van Steen, H. Frank, H. Billiet, T. Schalkhammer, F. Laugere, M. Vellekoop, A. Berthold, L. Sarro, G.W.K. Van Dedem, Capillary electrophoresis with on-chip four-electrode capacitively coupled conductivity detection for application in bioanalysis, Electrophoresis. 22 (2001) 2537-2541. https://doi.org/10.1002/15222683(200107)22:12<2537::AID-ELPS2537>3.0.CO;2-C.

[28] D.E. Scott, R.J. Grigsby, S.M. Lunte, Microdialysis sampling coupled to microchip electrophoresis with integrated amperometric detection on an all-glass substrate, ChemPhysChem. 14 (2013) 2288-2294. https://doi.org/10.1002/cphc.201300449.

[29] I. Chartier, J. Sudor, Y. Fouillet, N. Sarrut, C. Bory, A. Gruss, Fabrication of a hybrid plasticsilicon microfluidic device for high-throughput genotyping, in: H. Becker, P. Woias (Eds.), Microfluidics, BioMEMS, and Medical Microsystems, 2003: p. 208.

https://doi.org/10.1117/12.478146.

[30] L.P. Bressan, D.P. de Jesus, D.B. Gunasekara, S.M. Lunte, J.A.F. da Silva, Microchip electrophoresis containing electrodes for integrated electrochemical detection, in: Methods in Molecular Biology, Humana Press Inc., 2019: pp. 79-85. https://doi.org/10.1007/978-14939-8964-5_5. 
[31] F. Caxico de Abreu, E.E.M. Costa, Electrochemical Detection Using an Engraved Microchip Capillary Electrophoresis Platform, Electroanalysis. 28 (2016) 2104-2108. https://doi.org/10.1002/elan.201600033.

[32] C.W. Tsao, Polymer microfluidics: Simple, low-cost fabrication process bridging academic lab research to commercialized production, Micromachines. 7 (2016) 225. https://doi.org/10.3390/mi7120225.

[33] E.M. Erro, P.I. Ortiz, A comparative study of different microchips for capillary electrophoresis with electrochemical detection, Journal of Applied Electrochemistry. 44 (2014) 1393-1399. https://doi.org/10.1007/s10800-014-0764-1.

[34] A.D. Castiaux, E.R. Currens, R.S. Martin, Direct embedding and versatile placement of electrodes in 3D printed microfluidic-devices, The Analyst. (2020). https://doi.org/10.1039/d0an00240b.

[35] J.W. Lee, D. Lee, Y.T. Kim, E.Y. Lee, D.H. Kim, T.S. Seo, Low-cost and facile fabrication of a paper-based capillary electrophoresis microdevice for pathogen detection, Biosensors and Bioelectronics. 91 (2017) 388-392. https://doi.org/10.1016/j.bios.2016.12.053.

[36] A. Manz, D.J. Harrison, E.M.J. Verpoorte, J.C. Fettinger, A. Paulus, H. Lüdi, H.M. Widmer, Planar chips technology for miniaturization and integration of separation techniques into monitoring systems. Capillary electrophoresis on a chip, Journal of Chromatography A. 593 (1992) 253-258. https://doi.org/10.1016/0021-9673(92)80293-4.

[37] D.C. Duffy, J.C. Mcdonald, O.J.A. Schueller, G.M. Whitesides, Rapid prototyping of microfluidic systems in poly(dimethylsiloxane), Analytical Chemistry. 70 (1998) 4974-4984.

[38] C.C. Liu, D.F. Cui, Design and fabrication of poly(dimethylsiloxane) electrophoresis microchip with integrated electrodes, Microsystem Technologies. 11 (2005) 1262-1266. https://doi.org/10.1007/s00542-005-0608-3.

[39] J.C. McDonald, D.C. Duffy, J.R. Anderson, D.T. Chiu, H. Wu, O.J.A. Schueller, G.M. Whitesides, Fabrication of microfluidic systems in poly(dimethylsiloxane), Electrophoresis. 21 (2000) 2740. https://doi.org/10.1002/(SICI)1522-2683(20000101)21:1<27::AID-ELPS27>3.0.CO;2-C.

[40] S.K. Sia, G.M. Whitesides, Microfluidic devices fabricated in poly(dimethylsiloxane) for biological studies, Electrophoresis. 24 (2003) 3563-3576.

https://doi.org/10.1002/elps.200305584.

[41] E.O. Lobo-Júnior, E.F.M. Gabriel, R.A. dos Santos, F.R. de Souza, W.D. Lopes, R.S. Lima, A.L. Gobbi, W.K.T. Coltro, Simple, rapid and, cost-effective fabrication of PDMS electrophoresis microchips using poly(vinyl acetate) as photoresist master, Electrophoresis. 38 (2017) 250257. https://doi.org/10.1002/elps.201600209.

[42] E. Gencturk, S. Mutlu, K.O. Ulgen, Advances in microfluidic devices made from thermoplastics used in cell biology and analyses, Biomicrofluidics. 11 (2017) 051502.

https://doi.org/10.1063/1.4998604.

[43] A.W. Martinez, S.T. Phillips, G.M. Whitesides, E. Carrilho, Diagnostics for the developing world: Microfluidic paper-based analytical devices, Analytical Chemistry. 82 (2010) 3-10. https://doi.org/10.1021/ac9013989. 
[44] W. Dungchai, O. Chailapakul, C.S. Henry, Electrochemical detection for paper-based microfluidics, Analytical Chemistry. 81 (2009) 5821-5826. https://doi.org/10.1021/ac9007573.

[45] A. Abdollahi Aghdam, M.R. Majidi, H. Veladi, Y. Omidi, Microfluidic-based separation and detection of synthetic antioxidants by integrated gold electrodes followed by HPLC-DAD, Microchemical Journal. 149 (2019) 104059. https://doi.org/10.1016/j.microc.2019.104059.

[46] A. Fernández-La-Villa, V. Bertrand-Serrador, D.F. Pozo-Ayuso, M. Castaño-Álvarez, Fast and reliable urine analysis using a portable platform based on microfluidic electrophoresis chips with electrochemical detection, Analytical Methods. 5 (2013) 1494-1501. https://doi.org/10.1039/c2ay26166a.

[47] A. Fernández-la-Villa, D. Sánchez-Barragán, D.F. Pozo-Ayuso, M. Castaño-Álvarez, Smart portable electrophoresis instrument based on multipurpose microfluidic chips with electrochemical detection, Electrophoresis. 33 (2012) 2733-2742. https://doi.org/10.1002/elps.201200236.

[48] R.P. Baldwin, T.J. Roussel, M.M. Crain, V. Bathlagunda, D.J. Jackson, J. Gullapalli, J.A. Conklin, R. Pai, J.F. Naber, K.M. Walsh, R.S. Keynton, Fully Integrated On-Chip Electrochemical Detection for Capillary Electrophoresis in a Microfabricated Device, Analytical Chemistry. 74 (2002) 3690-3697. https://doi.org/10.1021/ac011188n.

[49] D.B. Gunasekara, M.B. Wijesinghe, P. Pichetsurnthorn, S.M. Lunte, Evaluation of dual electrode configurations for microchip electrophoresis used for voltammetric characterization of electroactive species, Analyst. 145 (2020) 865-872. https://doi.org/10.1039/c9an02112d.

[50] M. Castaño-Álvarez, M.T. Fernández-Abedul, A. Costa-García, M. Agirregabiria, L.J. Fernández, J.M. Ruano-López, B. Barredo-Presa, Fabrication of SU-8 based microchip electrophoresis with integrated electrochemical detection for neurotransmitters, Talanta. 80 (2009) 24-30. https://doi.org/10.1016/j.talanta.2009.05.049.

[51] D.J. Jackson, J.F. Naber, T.J. Roussel, M.M. Crain, K.M. Walsh, R.S. Keynton, R.P. Baldwin, Portable High-Voltage Power Supply and Electrochemical Detection Circuits for Microchip Capillary Electrophoresis, Analytical Chemistry. 75 (2003) 3643-3649.

https://doi.org/10.1021/ac0206622.

[52] A. Bonabi, S. Tähkä, E. Ollikainen, V. Jokinen, T. Sikanen, Metallization of organically modified ceramics for microfluidic electrochemical assays, Micromachines. 10 (2019) 1-12. https://doi.org/10.3390/mi10090605.

[53] A. Jankowski, J. Hayes, The evaporative deposition of aluminum coatings and shapes with grain size control, in: Thin Solid Films, Elsevier, 2004: pp. 568-574. https://doi.org/10.1016/j.tsf.2003.07.018.

[54] C. Chen, W. Teng, J.H. Hahn, Nanoband electrode for high-performance in-channel amperometric detection in dual-channel microchip capillary electrophoresis, Electrophoresis. 32 (2011) 838-843. https://doi.org/10.1002/elps.201000661.

[55] M. Nordström, A. Johansson, E.S. Noguerón, B. Clausen, M. Calleja, A. Boisen, Investigation of the bond strength between the photo-sensitive polymer SU-8 and gold, in: Microelectronic Engineering, Elsevier, 2005: pp. 152-157. https://doi.org/10.1016/j.mee.2004.12.021. 
[56] A.N. Pargellis, Evaporating and sputtering: Substrate heating dependence on deposition rate, Journal of Vacuum Science \& Technology A: Vacuum, Surfaces, and Films. 7 (1989) 27-30. https://doi.org/10.1116/1.575762.

[57] H. Becker, U. Heim, Hot embossing as a method for the fabrication of polymer high aspect ratio structures, Sensors and Actuators, A: Physical. 83 (2000) 130-135. https://doi.org/10.1016/S0924-4247(00)00296-X.

[58] Y.A. Yang, C.H. Lin, Y.C. Wei, Thread-based microfluidic system for detection of rapid blood urea nitrogen in whole blood, Microfluidics and Nanofluidics. 16 (2014) 887-894. https://doi.org/10.1007/s10404-014-1338-6.

[59] A. Selimovic, A.S. Johnson, I.Z. Kiss, R.S. Martin, Use of epoxy-embedded electrodes to integrate electrochemical detection with microchip-based analysis systems, Electrophoresis. 32 (2011) 822-831. https://doi.org/10.1002/elps.201000665.

[60] A.S. Johnson, K.B. Anderson, S.T. Halpin, D.C. Kirkpatrick, D.M. Spence, R.S. Martin, Integration of multiple components in polystyrene-based microfluidic devices part I: Fabrication and characterization, Analyst. 138 (2013) 129-136. https://doi.org/10.1039/c2an36168j.

[61] D.M.R. de Rooij, Electrochemical Methods: Fundamentals and Applications, Anti-Corrosion Methods and Materials. 50 (2003). https://doi.org/10.1108/acmm.2003.12850eae.001.

[62] S. Ranganathan, R.L. McCreery, Electroanalytical performance of carbon films with nearatomic flatness, Analytical Chemistry. 73 (2001) 893-900.

https://doi.org/10.1021/ac0007534.

[63] R.A. Saylor, E.A. Reid, S.M. Lunte, Microchip electrophoresis with electrochemical detection for the determination of analytes in the dopamine metabolic pathway, Electrophoresis. 36 (2015) 1912-1919. https://doi.org/10.1002/elps.201500150.

[64] A.J. Gawron, R.S. Martin, S.M. Lunte, Fabrication and evaluation of a carbon-based dualelectrode detector for poly(dimethylsiloxane) electrophoresis chips, ELECTROPHORESIS. 22 (2001) 242-248. https://doi.org/10.1002/1522-2683(200101)22:2<242::AIDELPS242>3.0.CO;2-W.

[65] H. Cheng, W.H. Huang, R.S. Chen, Z.L. Wang, J.K. Cheng, Carbon fiber nanoelectrodes applied to microchip electrophoresis amperometric detection of neurotransmitter dopamine in rat pheochromocytoma (PC12) cells, Electrophoresis. 28 (2007) 1579-1586. https://doi.org/10.1002/elps.200600603.

[66] W.H. Huang, D.W. Pang, H. Tong, Z.L. Wang, J.K. Cheng, A method for the fabrication of lownoise carbon fiber nanoelectrodes, Analytical Chemistry. 73 (2001) 1048-1052. https://doi.org/10.1021/ac0008183.

[67] R.N. Adams, Carbon Paste Electrodes, Analytical Chemistry. 30 (1958) 1576. https://doi.org/10.1021/ac60141a600.

[68] R.S. Martin, A.J. Gawron, B.A. Fogarty, F.B. Regan, E. Dempsey, S.M. Lunte, Carbon pastebased electrochemical detectors for microchip capillary electrophoresis/electrochemistry, Analyst. 126 (2001) 277-280. https://doi.org/10.1039/b009827m. 
[69] A. Regel, S. Lunte, Integration of a graphite/poly(methyl-methacrylate) composite electrode into a poly(methylmethacrylate) substrate for electrochemical detection in microchips, Electrophoresis. 34 (2013) 2101-2106. https://doi.org/10.1002/elps.201300055.

[70] J. Gouyon, F. d'Orlyé, S. Griveau, F. Bedioui, A. Varenne, Characterization of home-made graphite/PDMS microband electrodes for amperometric detection in an original reusable glass-NOA ${ }^{\circledR}$-PDMS electrophoretic microdevice, Electrochimica Acta. 329 (2020). https://doi.org/10.1016/j.electacta.2019.135164.

[71] J. Castillo- León, W. Svendsen, Lab-on-a-Chip Devices and Micro-Total Analysis Systems, Springer, 2015. https://doi.org/10.1007/978-3-319-08687-3.

[72] D.J. Fischer, M.K. Hulvey, A.R. Regel, S.M. Lunte, Amperometric detection in microchip electrophoresis devices: Effect of electrode material and alignment on analytical performance, Electrophoresis. 30 (2009) 3324-3333. https://doi.org/10.1002/elps.200900317.

[73] L.C. Mecker, R.S. Martin, Integration of microdialysis sampling and microchip electrophoresis with electrochemical detection, Analytical Chemistry. 80 (2008) 9257-9264. https://doi.org/10.1021/ac801614r.

[74] J.M. Petroni, B.G. Lucca, V.S. Ferreira, Simple approach for the fabrication of screen-printed carbon-based electrode for amperometric detection on microchip electrophoresis, Analytica Chimica Acta. 954 (2017) 88-96. https://doi.org/10.1016/j.aca.2016.12.027.

[75] C.L.S. Chagas, L. Costa Duarte, E.O. Lobo-Júnior, E. Piccin, N. Dossi, W.K.T. Coltro, Hand drawing of pencil electrodes on paper platforms for contactless conductivity detection of inorganic cations in human tear samples using electrophoresis chips, Electrophoresis. 36 (2015) 1837-1844. https://doi.org/10.1002/elps.201500110.

[76] C.L.S. Chagas, F.R. De Souza, T.M.G. Cardoso, R.C. Moreira, J.A.F. Da Silva, D.P. De Jesus, W.K.T. Coltro, A fully disposable paper-based electrophoresis microchip with integrated pencil-drawn electrodes for contactless conductivity detection, Analytical Methods. 8 (2016) 6682-6686. https://doi.org/10.1039/c6ay01963c.

[77] D. Shin, D.A. Tryk, A. Fujishima, A. Muck, G. Chen, J. Wang, Microchip capillary electrophoresis with a boron-doped diamond electrochemical detector for analysis of aromatic amines, Electrophoresis. 25 (2004) 3017-3023. https://doi.org/10.1002/elps.200305965.

[78] J. Wang, G. Chen, M.P. Chatrathi, A. Fujishima, D.A. Tryk, D. Shin, Microchip capillary electrophoresis coupled with a boron-doped diamond electrode-based electrochemical detector, Analytical Chemistry. 75 (2003) 935-939. https://doi.org/10.1021/ac0262053.

[79] L.G. Shaidarova, G.K. Budnikov, Chemically modified electrodes based on noble metals, polymer films, or their composites in organic voltammetry, Journal of Analytical Chemistry. 63 (2008) 922-942. https://doi.org/10.1134/S106193480810002X.

[80] T. Sierra, A.G. Crevillen, A. Escarpa, Electrochemical detection based on nanomaterials in CE and microfluidic systems, ELECTROPHORESIS. 40 (2019) 113-123.

https://doi.org/10.1002/ELPS.201800281. 
[81] L. García-Carmona, A. Martín, T. Sierra, M.C. González, A. Escarpa, Electrochemical detectors based on carbon and metallic nanostructures in capillary and microchip electrophoresis, Electrophoresis. 38 (2017) 80-94. https://doi.org/10.1002/elps.201600232.

[82] G. Zhu, Q. Song, W. Liu, X. Yan, J. Xiao, C. Chen, A gold nanoparticle-modified indium tin oxide microelectrode for in-channel amperometric detection in dual-channel microchip electrophoresis, Analytical Methods. 9 (2017) 4319-4326. https://doi.org/10.1039/c7ay01008g.

[83] Y. Li, C. Sella, F. Lemaître, M. Guille-Collignon, L. Thouin, C. Amatore, Electrochemical detection of nitric oxide and peroxynitrite anion in microchannels at highly sensitive platinumblack coated electrodes. application to ROS and RNS mixtures prior to biological investigations, Electrochimica Acta. 144 (2014) 111-118. https://doi.org/10.1016/j.electacta.2014.08.046.

[84] A. Selimovic, R.S. Martin, Encapsulated electrodes for microchip devices: Microarrays and platinized electrodes for signal enhancement, Electrophoresis. 34 (2013) 2092-2100. https://doi.org/10.1002/elps.201300163.

[85] C.K. Chua, M. Pumera, Chemically modified graphenes as detectors in lab-on-chip device, Electroanalysis. 25 (2013) 945-950. https://doi.org/10.1002/elan.201200583.

[86] B.G. Lucca, F. de Lima, W.K.T. Coltro, V.S. Ferreira, Electrodeposition of reduced graphene oxide on a Pt electrode and its use as amperometric sensor in microchip electrophoresis, Electrophoresis. 36 (2015) 1886-1893. https://doi.org/10.1002/elps.201500092.

[87] F. Du, Y.S. Fung, Dual-opposite multi-walled carbon nanotube modified carbon fiber microelectrode for microfluidic chip-capillary electrophoresis determination of methyl parathion metabolites in human urine, Electrophoresis. 39 (2018) 1375-1381. https://doi.org/10.1002/elps.201700470.

[88] F.J.V. Gomez, A. Martín, M.F. Silva, A. Escarpa, Microchip electrophoresis-single wall carbon nanotube press-transferred electrodes for fast and reliable electrochemical sensing of melatonin and its precursors, Electrophoresis. 36 (2015) 1880-1885. https://doi.org/10.1002/elps.201400580.

[89] L.A. Filla, D.C. Kirkpatrick, R.S. Martin, Use of a corona discharge to selectively pattern a hydrophilic/hydrophobic interface for integrating segmented flow with microchip electrophoresis and electrochemical detection, Analytical Chemistry. 83 (2011) 5996-6003. https://doi.org/10.1021/ac201007s.

[90] C.C. Wu, R.G. Wu, J.G. Huang, Y.C. Lin, H.C. Chang, Three-electrode electrochemical detector and platinum film decoupler integrated with a capillary electrophoresis microchip for amperometric detection, Analytical Chemistry. 75 (2003) 947-952. https://doi.org/10.1021/ac025912t.

[91] D.M. Osbourn, C.E. Lunte, Cellulose acetate decoupler for on-column electrochemical detection in capillary electrophoresis, Analytical Chemistry. 73 (2001) 5961-5964. https://doi.org/10.1021/ac010496i.

[92] D.M. Osbourn, C.E. Lunte, On-column electrochemical detection for microchip capillary electrophoresis, Analytical Chemistry. 75 (2003) 2710-2714.

https://doi.org/10.1021/ac026354l. 
[93] R.S. Martin, K.L. Ratzlaff, B.H. Huynh, S.M. Lunte, In-Channel Electrochemical Detection for Microchip Capillary Electrophoresis Using an Electrically Isolated Potentiostat, (2002). https://doi.org/10.1021/ac011087p.

[94] C. Chen, J.H. Hahn, Dual-channel method for interference-free in-channel amperometric detection in microchip capillary electrophoresis, Analytical Chemistry. 79 (2007) 7182-7186. https://doi.org/10.1021/ac070721h.

[95] P. Ertl, C.A. Emrich, P. Singhal, R.A. Mathies, Capillary electrophoresis chips with a sheath-flow supported electrochemical detection system, Analytical Chemistry. 76 (2004) 3749-3755. https://doi.org/10.1021/ac035282a.

[96] Q. Guan, C.S. Henry, Improving MCE with electrochemical detection using a bubble cell and sample stacking techniques, Electrophoresis. 30 (2009) 3339-3346. https://doi.org/10.1002/elps.200900316.

[97] T. Sierra, A.G. Crevillen, A. Escarpa, Determination of Glycoproteins by Microchip Electrophoresis Using Os(VI)-Based Selective Electrochemical Tag, Analytical Chemistry. 91 (2019) 10245-10250. https://doi.org/10.1021/ACS.ANALCHEM.9B02375.

[98] M. Pumera, A. Merkoĉo, S. Alegret, Microchip electrophoresis with wall-jet electrochemical detector: Influence of detection potential upon resolution of solutes, Electrophoresis. 27 (2006) 5068-5072. https://doi.org/10.1002/elps.200600386.

[99] R.F. Quero, L.P. Bressan, J.A.F. da Silva, D.P. de Jesus, A novel thread-based microfluidic device for capillary electrophoresis with capacitively coupled contactless conductivity detection, Sensors and Actuators, B: Chemical. 286 (2019) 301-305. https://doi.org/10.1016/j.snb.2019.01.168.

[100] W.K.T. Coltro, R.S. Lima, T.P. Segato, E. Carrilho, D.P. De Jesus, C.L. Do Lago, J.A.F. Da Silva, Capacitively coupled contactless conductivity detection on microfluidic systems - Ten years of development, Analytical Methods. 4 (2012) 25-33. https://doi.org/10.1039/c1ay05364g.

[101] H. Shadpour, M.L. Hupert, D. Patterson, C. Liu, M. Galloway, W. Stryjewski, J. Goettert, S.A. Soper, Multichannel microchip electrophoresis device fabricated in polycarbonate with an integrated contact conductivity sensor array, Analytical Chemistry. 79 (2007) 870-878. https://doi.org/10.1021/ac0612168.

[102] S.D. Noblitt, C.S. Henry, Improving the compatibility of contact conductivity detection with microchip electrophoresis using a bubble cell, Analytical Chemistry. 80 (2008) 7624-7630. https://doi.org/10.1021/ac8013862.

[103] F. Laugere, R.M. Guijt, J. Bastemeijer, G. Van der Steen, A. Berthold, E. Baltussen, P. Sarro, G.W.K. Van Dedem, M. Vellekoop, A. Bossche, On-chip contactless four-electrode conductivity detection for capillary electrophoresis devices, Analytical Chemistry. 75 (2003) 306-312. https://doi.org/10.1021/ac0157371.

[104] P. Tůma, F. Opekar, I. Jelínek, A contactless conductometric detector with easily exchangeable capillary for capillary electrophoresis, Electroanalysis. 13 (2001) 989-992. https://doi.org/10.1002/1521-4109(200108)13:12<989::AID-ELAN989>3.0.CO;2-C. 
[105] M. Pumera, J. Wang, F. Opekar, I. Jelinek, J. Feldman, H. Löwe, S. Hardt, Contactless conductivity detector for microchip capillary electrophoresis, Analytical Chemistry. 74 (2002) 1968-1971. https://doi.org/10.1021/ac011219e.

[106] P. Kubáň, P.C. Hauser, Effects of the cell geometry and operating parameters on the performance of an external contactless conductivity detector for microchip electrophoresis, Lab on a Chip. 5 (2005) 407-415. https://doi.org/10.1039/b418845d.

[107] G.F. Duarte Junior, J.A.F. Da Silva, K.J. Mendonça Francisco, C.L. do Lago, E. Carrilho, W.K.T. Coltro, Metalless electrodes for capacitively coupled contactless conductivity detection on electrophoresis microchips, Electrophoresis. 36 (2015) 1935-1940. https://doi.org/10.1002/elps.201500033.

[108] K.M. Schilly, S.M. Gunawardhana, M.B. Wijesinghe, S.M. Lunte, Biological applications of microchip electrophoresis with amperometric detection: in vivo monitoring and cell analysis, Analytical and Bioanalytical Chemistry. (2020). https://doi.org/10.1007/s00216-020-02647-z.

[109] A.L. Bowen, R.S. Martin, Integration of on-chip peristaltic pumps and injection valves with microchip electrophoresis and electrochemical detection, Electrophoresis. 31 (2010) 25342540. https://doi.org/10.1002/elps.201000029.

[110] A.S. Johnson, B.T. Mehl, R. Scott Martin, Integrated hybrid polystyrene-polydimethylsiloxane device for monitoring cellular release with microchip electrophoresis and electrochemical detection, Analytical Methods. 7 (2015) 884-893. https://doi.org/10.1039/c4ay02569e.

[111] B.T. Mehl, R.S. Martin, Integrating 3D cell culture of PC12 cells with microchip-based electrochemical detection, Analytical Methods. 11 (2019) 1064-1072. https://doi.org/10.1039/c8ay02672f.

[112] D.E. Scott, S.D. Willis, S. Gabbert, D. Johnson, E. Naylor, E.M. Janle, J.E. Krichevsky, C.E. Lunte, S.M. Lunte, Development of an on-animal separation-based sensor for monitoring drug metabolism in freely roaming sheep, Analyst. 140 (2015) 3820-3829. https://doi.org/10.1039/c4an01928h.

[113] D.M. Tsai, K.W. Lin, J.M. Zen, H.Y. Chen, R.H. Hong, A new fabrication process for a microchip electrophoresis device integrated with a three-electrode electrochemical detector, Electrophoresis. 26 (2005) 3007-3012. https://doi.org/10.1002/elps.200500107.

[114] J.C. Fanguy, C.S. Henry, The analysis of uric acid in urine using microchip capillary electrophoresis with electrochemical detection, ELECTROPHORESIS. 23 (2002) 767-773. https://doi.org/10.1002/1522-2683(200203)23:5<767::AID-ELPS767>3.0.CO;2-8.

[115] A. Fernández-La-Villa, V. Bertrand-Serrador, D.F. Pozo-Ayuso, M. Castaño-Álvarez, Fast and reliable urine analysis using a portable platform based on microfluidic electrophoresis chips with electrochemical detection, Analytical Methods. 5 (2013) 1494-1501. https://doi.org/10.1039/c2ay26166a.

[116] D. Meneses, D.B. Gunasekara, P. Pichetsurnthorn, J.A.F. da Silva, F.C. de Abreu, S.M. Lunte, Evaluation of in-channel amperometric detection using a dual-channel microchip electrophoresis device and a two-electrode potentiostat for reverse polarity separations, Electrophoresis. 36 (2015) 441-448. https://doi.org/10.1002/elps.201400297. 
[117] A. Schuchert-Shi, P.C. Hauser, Monitoring the enzymatic conversion of urea to ammonium by conventional or microchip capillary electrophoresis with contactless conductivity detection, Analytical Biochemistry. 376 (2008) 262-267. https://doi.org/10.1016/j.ab.2008.02.030.

[118] S. Zhang, W. Cao, J. Li, M. Su, MCE enzyme immunoassay for carcinoembryonic antigen and alpha- fetoprotein using electrochemical detection, Electrophoresis. 30 (2009) 3427-3435. https://doi.org/10.1002/elps.200800805.

[119] Z. Song, Y. Xu, Z. Chen, J. Yang, X. Li, Z. Zhang, Quantification of lactate in synovia by microchip with contactless conductivity detection, Analytical Biochemistry. 434 (2013) 73-77. https://doi.org/10.1016/j.ab.2012.11.006.

[120] K.C. Chong, L.Y. Thang, J.P. Quirino, H.H. See, Monitoring of vancomycin in human plasma via portable microchip electrophoresis with contactless conductivity detector and multi-stacking strategy, Journal of Chromatography A. 1485 (2017) 142-146. https://doi.org/10.1016/j.chroma.2017.01.012.

[121] S.P. Chen, X.D. Yu, J.J. Xu, H.Y. Chen, Gold nanoparticles-coated magnetic microspheres as affinity matrix for detection of hemoglobin A1c in blood by microfluidic immunoassay, Biosensors and Bioelectronics. 26 (2011) 4779-4784. https://doi.org/10.1016/j.bios.2011.06.001.

[122] S. Staal, M. Ungerer, A. Floris, H.W. ten Brinke, R. Helmhout, M. Tellegen, K. Janssen, E. Karstens, C. van Arragon, S. Lenk, E. Staijen, J. Bartholomew, H. Krabbe, K. Movig, P. Dubský, A. van den Berg, J. Eijkel, A versatile electrophoresis-based self-test platform, Electrophoresis. 36 (2015) 712-721. https://doi.org/10.1002/elps.201400428.

[123] P. Kubáň, P.C. Hauser, Evaluation of microchip capillary electrophoresis with external contactless conductivity detection for the determination of major inorganic ions and lithium in serum and urine samples, Lab on a Chip. 8 (2008) 1829-1836.

https://doi.org/10.1039/b802973c.

[124] G.F. Duarte-Junior, A. Ismail, S. Griveau, F. D’Orlyé, J.A. Fracassi Da Silva, W.K.T. Coltro, F. Bedioui, A. Varenne, Integrated microfluidic device for the separation, decomposition and detection of low molecular weight S-nitrosothiols, Analyst. 144 (2019) 180-185. https://doi.org/10.1039/c8an00757h.

[125] M. Vázquez, C. Frankenfeld, W.K.T. Coltro, E. Carrilho, D. Diamond, S.M. Lunte, Dual contactless conductivity and amperometric detection on hybrid PDMS/glass electrophoresis microchips, Analyst. 135 (2010) 96-103. https://doi.org/10.1039/b908985c.

[126] C.Y. Lee, C.M. Chen, G.L. Chang, C.H. Lin, L.M. Fu, Fabrication and characterization of semicircular detection electrodes for contactless conductivity detector - CE microchips, Electrophoresis. 27 (2006) 5043-5050. https://doi.org/10.1002/elps.200600113.

[127] T. Nogueira, C.L. do Lago, Determination of Ca, K, Mg, Na, sulfate, phosphate, formate, acetate, propionate, and glycerol in biodiesel by capillary electrophoresis with capacitively coupled contactless conductivity detection, Microchemical Journal. 99 (2011) 267-272. https://doi.org/10.1016/j.microc.2011.05.014.

[128] F. Du, Y.S. Fung, Development of CE-dual opposite carbon-fiber micro-disk electrode detection for peak purity assessment of polyphenols in red wine, Electrophoresis. 31 (2010) 2192-2199. https://doi.org/10.1002/elps.200900713. 
[129] J. Wang, M. Pumera, G.E. Collins, A. Mulchandani, Measurements of chemical warfare agent degradation products using an electrophoresis microchip with contactless conductivity detector, Analytical Chemistry. 74 (2002) 6121-6125. https://doi.org/10.1021/ac025746p.

[130] J. Wang, G. Chen, A. Muck, Movable contactless-conductivity detector for microchip capillary electrophoresis, Analytical Chemistry. 75 (2003) 4475-4479.

https://doi.org/10.1021/ac030122k.

[131] Y. Ding, C.D. Garcia, K.R. Rogers, Poly(dimethylsiloxane) microchip electrophoresis with contactless conductivity detection for measurement of chemical warfare agent degradation products, Analytical Letters. 41 (2008) 335-350.

https://doi.org/10.1080/00032710701792943.

[132] F. Della Pelle, M. Del Carlo, M. Sergi, D. Compagnone, A. Escarpa, Press-transferred carbon black nanoparticles on board of microfluidic chips for rapid and sensitive amperometric determination of phenyl carbamate pesticides in environmental samples, Microchimica Acta. 183 (2016) 3143-3149. https://doi.org/10.1007/s00604-016-1964-7. 